\title{
Mapping soil organic matter concentration at different scales using a mixed geographically weighted regression method
}

\author{
Canying Zeng a,c, Lin Yang b,*, A-Xing Zhu ${ }^{\text {a,b,c,d }}$, David G. Rossiter ${ }^{\text {a,e }}$, Jing Liu ${ }^{\text {d }}$, Junzhi Liu ${ }^{\text {a }}$, \\ Chengzhi Qin ${ }^{\mathrm{b}}$, Desheng Wang ${ }^{\mathrm{a}}$ \\ a Key Laboratory of Virtual Geographic Environment, Ministry of Education, Nanjing Normal University, 1 Wenyuan Road, Nanjing, Jiangsu 210023, China

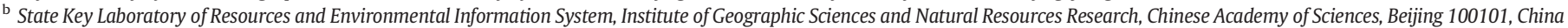 \\ c Jiangsu Center for Collaborative Innovation in Geographical Information Resource Development and Application, 1 Wenyuan Road, Nanjing, Jiangsu 210023, China \\ d Department of Geography, University of Wisconsin-Madison, Madison, USA \\ e School of Integrative Plant Sciences, Section of Soil \&' Crop Sciences, Cornell University, Ithaca, NY 14850, USA
}

\section{A R T I C L E I N F O}

Article history:

Received 21 January 2016

Received in revised form 22 April 2016

Accepted 27 June 2016

Available online 8 July 2016

\section{Keywords:}

Mixed geographically weighted regression (MGWR)

Geographically weighted regression (GWR)

Multiple linear regression (MLR)

Soil organic matter concentration (SOM)

\begin{abstract}
A B S T R A C T
The present regression models in digital soil mapping usually assume that relationships between soil properties and environmental variables are always fixed (as in MLR) or varying (as in GWR) in geographical space. In reality, some of the environmental variables may be fixed in affecting soil property variation and some are local varying. In this study, a mixed geographically weighted regression (MGWR) method which can deal with fixed and varying spatial relationships between a target variable and its environmental variables were proposed and used to predict topsoil soil organic matter (SOM) concentration in two study areas (Heshan, Heilongjiang province and Xuancheng, Anhui province, China) at two scales. Three groups of sample sets were created based on the total samples in the study areas to evaluate the robustness and stability of the model. Multiple linear regression (MLR), geographically weighted regression (GWR), GWR-kriging (GWRK), local regression-kriging (LRK), kriging with an external drift (KED), and ordinary kriging (OK) were used for comparison with MGWR. The validation results showed that the use of MGWR reduced the RMSE of GWR by $10.5 \%$ and $7.6 \%$ on average, reduced the RMSE of MLR by $12.8 \%$ and $9.9 \%$ on average for Heshan and Xuancheng study areas respectively. MGWR also showed a good competitiveness when compared with GWRK, LRK, KED and OK. In Heshan study area, the influence of flow length, relative position index, foot slope and distance to the nearest drainage were constant, whereas the elevation, topographic wetness index and valley index showed different influence in different regions. In Xuancheng study area, the fixed environmental variables were profile curvature, topographic wetness index and slope, whereas the varying environmental variables were precipitation, temperature, elevation, and limestone. The results indicate that the accuracy of predictions can be improved by adaptive coefficient according to the variation of environmental variables as implemented in MGWR compared with others considering only the local or global relationships. It was concluded that mixed geographically weighted regression model could be a potential method for digital soil mapping.
\end{abstract}

(c) 2016 Elsevier B.V. All rights reserved.

\section{Introduction}

Knowledge of soil spatial variation is essential for ecological processes modeling (Li, 2010; Du et al., 2015). Soil has long been considered as the result of the interaction of its formative environment, including climate, parent material, terrain, and vegetation conditions (Winklerprins, 1999; Mcbratney et al., 2003; Yang et al., 2008; Stoorvogel et al., 2009). Therefore, the relationships between soil and its environmental covariates can be used to map soil variations over space (Thompson et al., 2006; Sumfleth and Duttmann, 2008; Zhu et al., 2010).

\footnotetext{
* Corresponding author.

E-mail address: yanglin@lreis.ac.cn (L. Yang).
}

Numerous methods have been developed to predict soil spatial distribution based on the relationships between soil and its environmental covariates (Odeh and Mcbratney, 2000; Zhang et al., 2012; Zhao et al., 2014). Multiple linear regression (MLR) is one of those commonlyused methods in early time (Odeh and Mcbratney, 2000; Zornoza et al., 2007; Qiu et al., 2003; Chung and Alexander, 2002; Moore et al., 1993), and is usually used as a basic model comparing with other mapping methods (Zhu et al., 2010; Lesch et al., 1995; Qin et al., 2012; Song et al., 2016). The desirability for linear regression methods lies in its simplicity, easy to apply. However, it assumes that the relationships are multivariate linear and the same for the whole area. This is a strong assumption, especially over large areas. Although the relationships generated using methods such as decision tree and random forest are not the 
same or linear, these methods ignore the local spatial autocorrelation of soil properties (Henderson et al., 2005; Reza Pahlavan Rad et al., 2014; Taghizadeh-Mehrjardi et al., 2014). To consider both the relationships between soil properties and environmental covariates and spatial autocorrelation effect of soil property itself, regression kriging (RK), Kriging with External Drift (KED) were developed and widely used (Hengl et al., 2004; Hengl et al., 2007; Mishra et al., 2012; Bishop and Mcbratney, 2001). RK and KED combine a regression (usually multiple linear regression, but can also be a random forest etc.) of a target soil attribute on its environmental co-variables with kriging of the regression residuals. Many studies show higher accuracy than feature space-only models, due to the inclusion of spatial autocorrelation of model residuals in the models (Brus and Heuvelink, 2007; Odeh and Mcbratney, 2000; Sumfleth and Duttmann, 2008; Sun et al., 2012). However, the model residuals can't always tally with the first order or second order stationarity and seldom of these methods can be adapted to fit data locally with varying coefficients over space for the regression (Kumar et al., 2012; Walter et al., 2001).

To deal with the spatial non-stationarity of regression coefficients between a target variable and explanatory variables, geographically weighted regression (GWR) was developed to estimate varying coefficients of explanatory variables locally (Brunsdon and Fotheringham, 1999). Coefficients of GWR at each prediction point are estimated using a weighting matrix in which observations around a sampling point are weighted using a distance decay function, meaning that closer observations have a greater effect on the resulting localized regression coefficients. The spatial dependence of soil is accounted for by using the distance decay function. Many applications of GWR have shown good results for spatial non-stationarity modeling of soil variation (Mishra and Riley, 2012; Song et al., 2016; Wang et al., 2013; Zhang et al., 2011). However, the relationships between soil and some environmental covariates may be constant, not always varying as modeled in GWR in a given study area. For example, the effect of climate variables such as precipitation would be consistent for soil texture variation at a small watershed. Attempting to fit varying relations when they are not in fact present will be fitting random noise and thus result in poorer models. Further, model interpretation in terms of related or causative factors will be misleading.

Mixed geographically weighted regression (MGWR), an extension of GWR, was proposed to determine which predictors are fixed and varying over space (Fotheringham et al., 2002). It has been successfully applied in economics and agriculture (Mei et al., 2004; Pecci and Sassi, 2008; Qin et al., 2007; Wei and Qi, 2012). Qin et al. (2007) developed an iterative algorithm to estimate fixed and varying coefficients in MGWR and further tested it by using average prices of house blocks in Shanghai. MGWR gave superior model fits to GWR. In this test case the population density and unemployment rate showed fixed relations to the house prices over geographic space, whereas the distance to subway stations, greening rate and etc. varied.

MGWR has not been applied in soil mapping, although it would seem to be a promising approach due to its ability to discern fixed or constant independent variables. The relationships between soil and its environmental co-variables are known to be scale-dependent and varying in different soil landscapes. It is clear that not all environmental covariables affect the soil variable at the same scale. Think for example of regional climate, compared to local topographic effects. For a regional scale area, it is possible that the impact of even climate variables for soil is varying over the area. While for a small watershed area, climate variables would affect soil variation consistently for the area. As for topographic variables, the relationships between soil and topographic variables are usually varying. While for low relief areas with small coverage, the relationship between soil and some topographic variables may be consistent. Therefore, it is not appropriate always use local coefficients to describe the relationships as in GWR and an environmental variable will be not always fixed or varying in different regions depend on the characteristics of the study area. MGWR is able to determine which variables are fixed or varying over a given study area. It can be a potential method in digital soil mapping. Such model may lead to a new interpretation of the phenomena soil variation by considering both spatially stationary and non-stationary effects.

This paper aims to introduce MGWR into digital soil mapping. The method was used to predict the A-horizon soil organic matter (SOM) concentration in two study areas with different sampling densities, one with gentle terrain at watershed scale and the other with complex environmental conditions at regional scale. Fixed variables and varying variables for SOM in the two study areas were detected using MGWR. And to test the effectiveness of MWGR, GWR, MLR, GWRK (GWRkriging), LRK (local regression-kriging), KED (kriging with an external drift) and OK (ordinary kriging) were also applied to compare with MGWR.

\section{Study areas and data}

\subsection{Study areas}

Two study areas were selected with environmental conditions of different complexities at different scales (Fig. 1). The first study area is Heshan farm at a watershed scale with area about $60 \mathrm{~km}^{2}$, located in Nenjiang County of Heilongjiang province, China $\left(48^{\circ} 43^{\prime}\right.$ to $49^{\circ} 03^{\prime} \mathrm{N}$ and $124^{\circ} 56^{\prime}$ to $126^{\circ} 21^{\prime} \mathrm{W}$ ). This study area have a gentle environmental gradient with slope gradient mainly under $4^{\circ}$ and elevation varying from $276 \mathrm{~m}$ to $363 \mathrm{~m}$ above sea level. The land use is mainly cropland including soybean and wheat cropland. The parent materials are mainly silt loam loess over the whole area except in the valley bottom, which is mainly occupied by fluvial deposits. The average annual precipitation is about 500-600 $\mathrm{mm}$ and the annual temperature varies from $-38{ }^{\circ} \mathrm{C}$ to $36{ }^{\circ} \mathrm{C}$ with very cool climate in winter and warm climate in summer (Zhu et al., 2015). Land use, climate and parent materials in this study area have been fairly uniform (Yang et al., 2013; Zhu et al., 2010).

The second study area is Xuancheng county at a regional scale, located in Anhui province of China with an area of $5900 \mathrm{~km}^{2}\left(29^{\circ} 57^{\prime} \mathrm{N}-31^{\circ}\right.$ $19^{\prime} \mathrm{N}$ and $\left.117^{\circ} 58^{\prime} \mathrm{W}-119^{\circ} 40^{\prime} \mathrm{W}\right)$. The average annual precipitation in this area is $1200-1800 \mathrm{~mm}$ and the annual temperature is $11-16^{\circ} \mathrm{C}$, with cool and dry climate in winter and warm and humid climate in summer. The northwest of the area is low-relief and other areas are mountainous. "Land use mainly involves cultivated land with irrigated rice as the dominant crop, and secondary or planted forest land covered by bamboo, fir, shrub and other evergreen coniferous or deciduous broad-leafed trees. The soil parent materials in the study area are complex, including shale, sandstone, pyroclastic rocks, granite and granodiorite, limestone, conglomerate, quaternary clay-silt-gravel, quaternary vermicule boulder and grave clay" (Yang et al., 2016). The soil forming environment of this study area is complex mainly because of the complicated soil parent materials and variable landforms including plains, hills, and low mountains etc.

A-horizon SOM concentration in $\mathrm{g} / \mathrm{kg}$ fine soil ( $<2 \mathrm{~mm}$ particle size $)$ was the target soil property.

\subsection{Environmental data}

In the Heshan study area landform is the main environmental factor controlling the soil formation. Seventeen topographic factors were generated from the DEM using a terrain analysis software SimDTA (Qin et al., 2009a, 2009b) or Arcgis 10.1 (Table 1). A 10 m horizontal resolution Digital Elevation Model (DEM) was created from the 1:10,000 scale topographic map published by Chinese Bureau of Surveying and Mapping (1987).

In the Xuancheng study area, topographical, parent materials, vegetation and climate play important roles for soil formation (Yang et al., 2016). Twenty-four environmental factors were generated in this study area (Table 1). The topographic factors were derived from the DEM which obtained from the Shuttle Radar Topographic Mission 


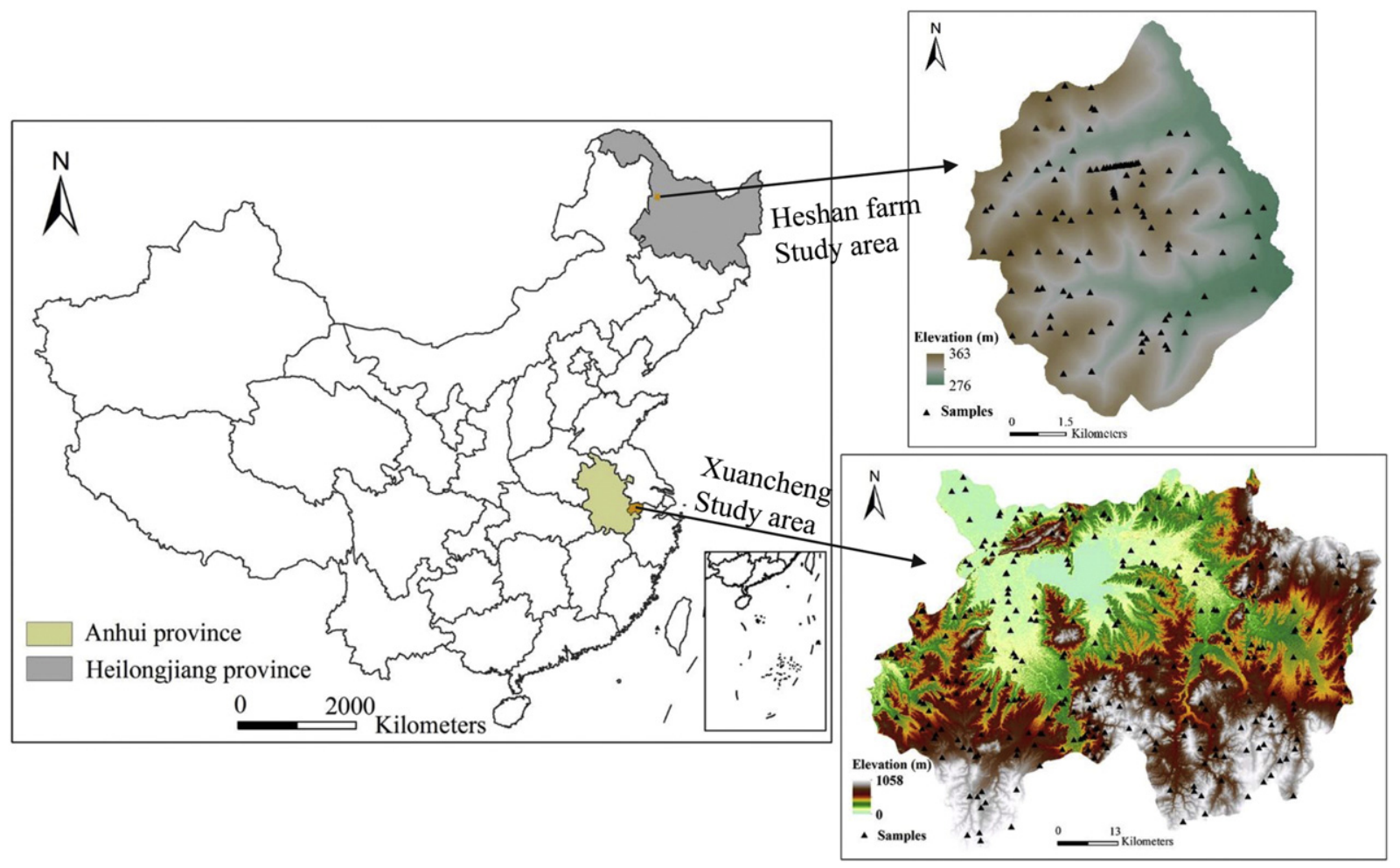

Fig. 1. Location and soil sample distribution of the Heshan farm study area and Xuancheng study area.

(SRTM) website (http://srtm.csi.cgiar.org/SELECTION/inputCoord.asp) with $90 \mathrm{~m}$ spatial resolution. The slope position was not included because it is difficult to calculate accurate slope positions based on the $90 \mathrm{~m}$ resolution DEM. The parent material was generated from the 1:500,000 geological map of China and individually coded as binary variables. The climate factors included annual average precipitation and annual average temperature, which were obtained from the Chinese Ecological Environment Database created by the Institute of Agricultural Resources and Regional Planning at the Chinese Academy of Agricultural Science. Their horizontal resolution were $1000 \mathrm{~m}$. The vegetation data include summer average Enhanced Vegetation Index (EVI) and annual average EVI in 2011 which obtained from the 16-day time series of 250 m MODIS vegetation indices (MOD13Q1) (http://ladsweb.nascom. nasa.gov/data/search.html). The parent materials, climate and EVI data were resampled to $90 \mathrm{~m}$ using a nearest neighbor interpolation.

All candidate variables were standardized (Yang et al., 2013). The profile curvature and plan curvature were stretched to $[-50,50]$, with the 0 values (indicating a linear slope along the curvature plane) remaining unchanged (a 0 value). Other candidate variables were standardized to $[0,100]$.

\subsection{Soil sampling and analysis}

One hundred and four sampling points in Heshan (with a density of $0.8 \mathrm{~km}^{2}$ per observation) and 295 sampling points in Xuancheng (with a density of $25 \mathrm{~km}^{2}$ per observation) were collected separately in

Table 1

Description of environmental covariates.

\begin{tabular}{|c|c|c|c|c|}
\hline & Variables & Module & Softwares & Study areas \\
\hline \multirow[t]{13}{*}{ Terrain } & Elevation & Elevation & Acgis 10.1 & Both \\
\hline & Slope & Slope in ArcInfo & Acgis 10.1 & Both \\
\hline & Planc & Plan curvature (Shary et al., 2002) & Acgis 10.1 & Both \\
\hline & Profic & Profile curvature (Shary et al., 2002) & Acgis 10.1 & Both \\
\hline & TWI & Topographic wetness index (Qin et al., 2009a,b) & SimDTA & Both \\
\hline & Hand & Height above the nearest drainage (Gharari et al., 2011) & Python & Both \\
\hline & Dand & Distance to the nearest drainage (Gharari et al., 2011) & Python & Both \\
\hline & TCI & Terrain characterization index (Park and Van De Giesen, 2004) & SimDTA & Both \\
\hline & TPI & Topographic position index (Jenness, 2005) & SimDTA & Both \\
\hline & Flowlen & Flow length based on MFD (Qin et al., 2007) & SimDTA & Both \\
\hline & ValleyI & Valley index & SimDTA & Both \\
\hline & RPI & Relative position index (Skidmore, 1990) & SimDTA & Both \\
\hline & \multicolumn{2}{|c|}{$\begin{array}{l}\text { Five binary variables based on fuzzy slope position (Qin et al., 2007) including ridge, shoulder slope (shoulder), back slope (back), } \\
\text { foot slope (foot), channel }\end{array}$} & SimDTA & Heshan \\
\hline \multirow[t]{2}{*}{ Climate } & Precipitation & Annual average precipitation & Acgis 10.1 & Xuancheng \\
\hline & Temperature & Annual average temperature & Acgis 10.1 & Xuancheng \\
\hline \multirow[t]{2}{*}{ Vegetation } & EVIs & Summer average EVI & Acgis 10.1 & Xuancheng \\
\hline & EVIa & Annual average EVI & Acgis 10.1 & Xuancheng \\
\hline Parent materials & \multicolumn{2}{|c|}{$\begin{array}{l}\text { Eight binary variables: shale, sandstone, pyroclastic rocks (pyroclastic), granite and granodiorite, limestone, conglomerate, } \\
\text { quaternary clay-silt-gravel (clay-silt-gravel), quaternary vermicule boulder and grave clay (grave clay) }\end{array}$} & Acgis 10.1 & Xuancheng \\
\hline
\end{tabular}


previous researches for various purposes (Yang et al., 2013; Zhang et al., 2016; Zhu et al., 2010) (Fig. 1). In Heshan, soil samples were collected through four sampling strategies: systematic sampling, integrative hierarchical stepwise sampling, subjective sampling, and transect sampling (Zhu et al., 2010; Yang et al., 2013). Forty four regular samples was arranged from $1100 \mathrm{~m} \times 740 \mathrm{~m}$ grid of study area. To collect representative (typical) samples for soil types in this area, an integrative hierarchical stepwise sampling method proposed by Yang et al. (2013) were used. Twenty nine points were collected. Ten subjective samples were collected to investigate areas with unique characteristics which located on summit, steep slope, and flood plain positions. Twenty one transect samples were collected which covered major environmental variations within the shortest distance from ridge top to valley bottom.

In Xuancheng, soil samples were collected through five sampling strategies: systematic sampling, integrative hierarchical stepwise sampling, stratified random sampling, a heuristic uncertainty directed field sampling, and subjective sampling by experts' experience (Zhang et al., 2016). Fifty eight samples were collected with $10 \mathrm{~km}$ by $10 \mathrm{~km}$ grid arrangement based on a systematic sampling strategy. Fifty one representative samples were collected using the integrative hierarchical stepwise sampling strategy in Yang et al. (2013). Sixty three samples were collected using a heuristic uncertainty directed sampling method in Zhang et al. (2016). 58 samples were collected using a stratified random sampling strategy using parent materials as strata (Zhang et al., 2016). The subjective sampling was conducted in farm land by the experience of expert with number of 65 .

Soil was sampled at A-horizon for both study areas. The soil organic matter concentration $(\mathrm{g} / \mathrm{kg})$ was measured for the collected samples. The soil samples were first air dried and sieved through a 2-mm mesh sieve. The dichromate oxidation method (external heat applied) was then used to measure the SOM concentration (Liu et al., 1996; Nelson and Sommers, 1982). The soil organic carbon was determined and then converted to SOM. The conversion factor is 1.724 and the additional factor is 1.1 to account for oxidation during the procedure.

The SOM data approximately follow a normal distribution (Fig. 2). For each study area, the sample set was split into a training dataset (70\% for Heshan, $80 \%$ for Xuancheng) and a validation dataset (30\% for Heshan, 20\% for Xuancheng) randomly. To test the stability of MGWR and other methods, the split was conducted three times, so that three groups of different training and validation data sets were generated for each study area.

\section{Methods}

\subsection{GWR and MGWR}

GWR models spatial relationships in neighborhoods by calibrating a varying coefficient regression model (Brunsdon and Fotheringham,
1999; Brunsdon et al., 1996) (Eq. (1)).

$y_{i}=\sum_{k} \beta_{k}\left(u_{i}, v_{i}\right) x_{i k}+\varepsilon_{i}$

where $y_{i}$ is the value of the soil organic matter at location $i ; x_{i k}$ is the value of the $k$ th environmental variable at location $i ; \beta_{k}\left(u_{i}, v_{i}\right)$ is the regression coefficient associated with the $k$ th environmental variable for location $i$ whose geographical coordinates are $\left(u_{i}, v_{i}\right) ; \varepsilon_{i}$ is the model error at location $i$. The difference between GWR and MLR is that the coefficients in GWR vary with locations but the coefficients in MLR are constant.

MGWR extends GWR by integrating geographically varying (or local) coefficients and globally fixed (or constant) coefficients in computation (Fotheringham et al., 2002; Helbich and Brunauer, 2016; Mei et al., 2004; Nakaya et al., 2009) (Eq. (2)):

$y_{i}=\sum_{k} \beta_{k}\left(u_{i}, v_{i}\right) x_{i k}+\sum_{l} \gamma_{l} z_{i l}+\varepsilon_{i}$

where $z_{i l}$ is the value of the $l$ th environmental variable whose regression coefficient $\gamma_{l}$ is fixed over space. By taking $x_{i 1}=1$ for all $i$, the model can include a fixed intercept. By taking $z_{i 1}=1$ for all $i$, the model can include a spatially varying intercept. By taking $x_{i k}=0$, the model is reduced to a MLR model. By taking $z_{i l}=0$, the model is reduced to a GWR model. Thus, the MGWR model mixed locally varying terms and globally fixed terms of environmental variables simultaneously.

The key innovation of MGWR is the determination of fixed and varying variables. Researchers may keep a subset of environment variables varying while holding others fixed based on their prior knowledge or intuition. However, it is more objective is to compare models having different combinations of fixed and varying coefficients (Nakaya et al., 2009; Nakaya, 2012). To do this, we compared models which have different combinations of fixed and varying variables iteratively. This approach is demonstrated as follows:

Step 1, a fitted GWR model (pivot model) is built in which a local regression model is fitted at each prediction location. The varying coefficients are estimated using in Eqs. (3)-(4) (Fotheringham et al., 2002).

$\hat{\beta}\left(u_{i}, v_{i}\right)=\left[X^{T} W\left(u_{i}, v_{i}\right) X\right]^{-1} X^{T} W\left(u_{i}, v_{i}\right) Y$

where $X$ is an $n \times o$ matrix consisting of $n$ observations of the environmental variables with varying coefficients, and $W\left(u_{i}, v_{i}\right)$ are the geographical spatial weights which emphasize that the samples are closer to the point to be predicted play a greater influence on the prediction results. The weights are determined by the weighting functions, also referred to as spatial kernels. The spatial kernel can be either fixed or adaptive. Due to our small sample size, we chose Gaussian fixed kernel function in which the kernel weight continuously and gradually decreases from the center of the kernel but never reaches zero so that
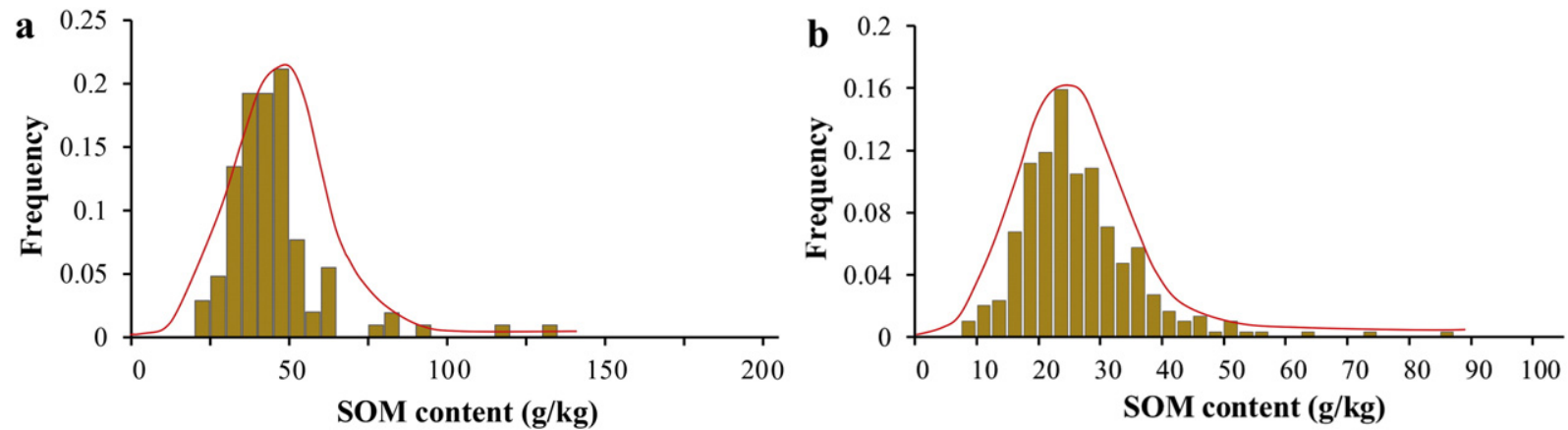

Fig. 2. Histograms of SOM data. (a) Hehshan study area (b) Xuancheng study area. Fitted approximately distribution shown as a curve. 
Table 2

Pearson correlation coefficients of SOM with candidate variables in Heshan.

\begin{tabular}{|c|c|c|c|c|c|c|c|c|c|}
\hline & Elevation & Slope & Planc & Profic & TWI & Hand & Dand & $\mathrm{TCI}$ & TPI \\
\hline Group 1 & $-0.50^{* *}$ & -0.03 & $-0.27^{*}$ & 0.13 & $0.38^{* *}$ & $-0.39^{* *}$ & $-0.31^{* *}$ & $-0.33^{* *}$ & $-0.24^{*}$ \\
\hline Group 2 & $-0.50^{* *}$ & -0.04 & -0.20 & 0.08 & $0.40^{* *}$ & $-0.42^{* *}$ & $-0.32^{* *}$ & $-0.26^{*}$ & -0.20 \\
\hline Group 3 & $-0.54^{* *}$ & -0.03 & $-0.26^{*}$ & 0.09 & $0.38^{* *}$ & $-0.48^{* *}$ & $-0.36^{* *}$ & $-0.30^{*}$ & -0.20 \\
\hline \multirow[t]{2}{*}{ All sample } & $-0.47^{* *}$ & -0.03 & -0.18 & 0.11 & $0.37^{* *}$ & $-0.38^{* *}$ & $-0.31^{* *}$ & $-0.26^{* *}$ & -0.19 \\
\hline & Flowlen & ValleyI & RPI & Ridge & Shoulder & Back & Foot & Channel & \\
\hline Group 1 & $-0.32^{* *}$ & $0.38^{* *}$ & $-0.34^{* *}$ & -0.12 & 0.23 & -0.20 & $0.37^{* *}$ & 0.22 & \\
\hline Group 2 & $-0.34^{* *}$ & $0.48^{* *}$ & $-0.34^{* *}$ & -0.09 & $0.24^{*}$ & -0.18 & $0.39^{* *}$ & 0.20 & \\
\hline Group 3 & $-0.36^{* *}$ & $0.47^{* *}$ & $-0.40^{* *}$ & -0.10 & 0.21 & 0.21 & $0.50^{* *}$ & $0.25^{*}$ & \\
\hline All sample & $-0.29 * *$ & $0.42^{* *}$ & $-0.34^{* *}$ & -0.11 & $0.23^{*}$ & -0.17 & $0.40^{* *}$ & 0.19 & \\
\hline
\end{tabular}

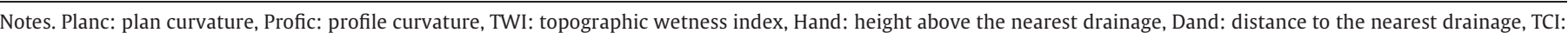

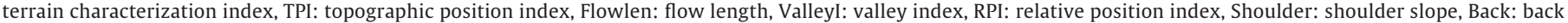
slope, Foot: foot slope. ${ }^{*}$ Correlation is significant at the 0.05 level (2-tailed), ${ }^{* *}$ Correlation is significant at the 0.01 level (2-tailed).

there is always some data within the kernel (Nakaya, 2012).

$W\left(u_{i}, v_{i}\right)=\exp \left(-d_{i j}^{2} / b^{2}\right)$

where $d_{i j}$ is the Euclidean distance between sample point $i$ and neighboring sample $j, b$ represents a basal width of the kernel function, called bandwidth.

Step 2, a new MGWR model is built, in which only one certain varying variable is switched to be fixed while coefficients of the other variables kept varying locally. The coefficients (fixed coefficient vector $\hat{\gamma}$ and varying coefficient vector $\left.\hat{\beta}\left(u_{i}, v_{i}\right)\right)$ are estimated using in Eqs. (5)-(7) (Mei et al., 2006; Mei et al., 2004; Nakaya et al., 2005).

$\hat{\gamma}=\left(\hat{\gamma}_{1}, \hat{\gamma}_{2}, \ldots, \hat{\gamma}\right)^{T}=\left[Z^{T}(I-S)^{T}(I-S) Z\right]^{-1}\left[Z^{T}(I-S)\right] Y$

where $Z$ is an $n \times m$ matrix consisting of $n$ observations of the fixed environmental variables; $m$ is the total number of these fixed environmental variables; $Y$ is a vector of $n$ observations on the soil organic matter; $I$ is an identity matrix of order $n$ and

$S=\left(\begin{array}{c}X_{1}^{T}\left[X^{T} W\left(u_{1}, v_{1}\right) X\right]^{-1} X^{T} W\left(u_{1}, v_{i}\right) \\ X_{2}^{T}\left[X^{T} W\left(u_{2}, v_{2}\right) X\right]^{-} X^{T} W\left(u_{2}, v_{2}\right) \\ \cdots \\ X_{n}^{T}\left[X^{T} W\left(u_{n}, v_{n}\right) X\right]^{-1} X^{T} W\left(u_{n}, v_{n}\right)\end{array}\right)$

where $X$ is an $n \times 0$ matrix consisting of $n$ observations of the environmental variables with varying coefficients; $o$ is the total number of these environmental variables with varying coefficients; $X_{n}^{T}$ is the $i$ th row of $X$. For the varying coefficient vector $\hat{\beta}\left(u_{i}, v_{i}\right)$ estimates is described as:

$\hat{\beta}\left(u_{i}, v_{i}\right)=\left[X^{T} W\left(u_{i}, v_{i}\right) X\right]^{-1} X^{T} W\left(u_{i}, v_{i}\right)(Y-Z \hat{\gamma})$

where $W\left(u_{i}, v_{i}\right)$ are the geographical spatial weights which also determined by the Eq. (4).

In order to calibrate the spatial weighting function and identify the optimal bandwidth for the models used in MGWR and GWR, the corrected Akaike information criterion (AICc) was applied. Given a collection of models for the data, AICc estimates the quality of each model, relative to each of the other models with a correction for finite sample sizes (Sugiura, 1978). A smaller AICc indicates optimal parsimony and, it is expected, predictive accuracy for the model. When the model is fitted with the geographical variability test, a golden section search is performed to find the optimal bandwidth size; the bandwidth with smallest AICc is selected.

Step 3, then AICc of the new MGWR model and the pivot model are compared (the smaller of AICc the better of the model). If the pivot model performs better than the new model by the model comparison criterion AICc, we can judge that the switched variables is certainly varying over space, otherwise it is fixed.

We repeat the above steps for each variables in the pivot model to finally confirm the fixed and varying variables, and a final MGWR model is built.

Table 3

Pearson correlation coefficients of SOM with candidate variables in Xuancheng

\begin{tabular}{|c|c|c|c|c|c|c|c|c|c|}
\hline & Elevation & Slope & Planc & Profic & TWI & Hand & Dand & $\mathrm{TCI}$ & TPI \\
\hline Group 1 & $0.47^{* *}$ & $0.45^{* *}$ & $0.14^{*}$ & $0.23^{*}$ & $-0.15^{*}$ & $0.34^{* *}$ & 0.001 & -0.1 & -0.08 \\
\hline Group 2 & $0.37^{* *}$ & $0.37^{* *}$ & $0.19^{* *}$ & $0.20^{* *}$ & $-0.14^{*}$ & $0.34^{* *}$ & -0.01 & -0.04 & -0.08 \\
\hline Group 3 & $0.44^{* *}$ & $0.42^{* *}$ & 0.13 & $0.18^{* *}$ & $-0.13^{*}$ & $0.32^{* *}$ & -0.03 & -0.04 & -0.01 \\
\hline \multirow[t]{2}{*}{ All sample } & $0.43^{* *}$ & $0.43^{* *}$ & $0.15^{* *}$ & $0.18^{* *}$ & $-0.15^{*}$ & $0.33^{* *}$ & 0.004 & -0.05 & -0.02 \\
\hline & Flowlen & ValleyI & RPI & Temperature & Precipitation & EVIs & EVIa & Shale & Sandstone \\
\hline Group 1 & $0.15^{*}$ & $0.22^{*}$ & -0.01 & $-0.43^{* *}$ & $0.41^{* *}$ & 0.10 & 0.02 & -0.01 & $0.26^{* *}$ \\
\hline Group 2 & $0.17^{* *}$ & -0.10 & -0.03 & $-0.36^{* *}$ & $0.32^{* *}$ & 0.11 & 0.03 & -0.01 & $0.21^{* *}$ \\
\hline Group 3 & $0.21^{* *}$ & $0.15^{*}$ & 0.06 & $-0.42^{* *}$ & $0.38^{* *}$ & 0.11 & 0.03 & 0.02 & $0.33^{* *}$ \\
\hline \multirow[t]{2}{*}{ All sample } & $0.15^{* *}$ & $0.19^{* *}$ & 0.006 & $-0.41^{* *}$ & $0.37^{* *}$ & 0.10 & 0.03 & 0.03 & $0.26^{* *}$ \\
\hline & Pyroclastic & \multicolumn{3}{|c|}{ Granite and granodiorite } & \multirow{2}{*}{$\begin{array}{l}\text { Limestone } \\
0.19^{* *}\end{array}$} & Conglomerate & \multicolumn{2}{|c|}{ Clay-silt-gravel } & Grave clay \\
\hline Group 1 & -0.09 & \multicolumn{3}{|c|}{$0.15^{*}$} & & $-0.13^{*}$ & \multicolumn{2}{|c|}{-0.08} & -0.12 \\
\hline Group 2 & -0.09 & \multicolumn{3}{|c|}{$0.19^{* *}$} & $0.17^{* *}$ & $-0.17^{* *}$ & \multicolumn{2}{|c|}{-0.08} & $-0.14^{*}$ \\
\hline Group 3 & -0.04 & \multicolumn{3}{|c|}{0.11} & $0.16^{* *}$ & -0.09 & \multicolumn{2}{|c|}{$-0.20^{* *}$} & -0.13 \\
\hline All sample & -0.07 & \multicolumn{2}{|c|}{$0.15^{*}$} & & $0.18^{* *}$ & $-0.13^{*}$ & \multicolumn{2}{|c|}{$-0.14^{*}$} & $-0.13^{*}$ \\
\hline
\end{tabular}

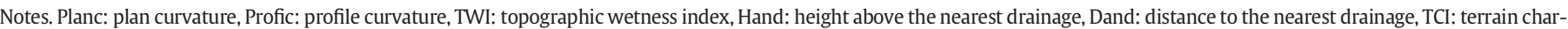

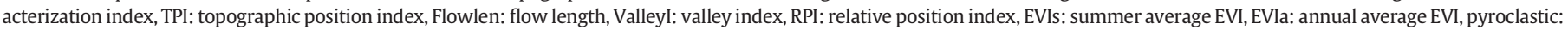

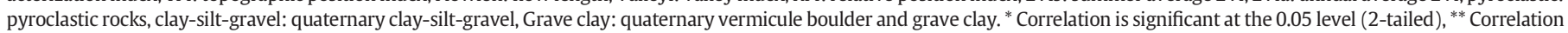
is significant at the 0.01 level (2-tailed). 
Table 4

Modeling accuracy of MLR, GWR and MGWR model for Heshan.

\begin{tabular}{|c|c|c|c|c|c|c|c|c|c|c|c|c|}
\hline & \multicolumn{3}{|l|}{ Group 1} & \multicolumn{3}{|l|}{ Group 2} & \multicolumn{3}{|l|}{ Group 3} & \multicolumn{3}{|l|}{ Average } \\
\hline & MLR & GWR & MGWR & MLR & GWR & MGWR & MLR & GWR & MGWR & MLR & GWR & MGWR \\
\hline $\mathrm{R}^{2}$ & 0.31 & 0.49 & 0.58 & 0.36 & 0.65 & 0.71 & 0.41 & 0.63 & 0.69 & 0.36 & 0.59 & 0.66 \\
\hline AICc & 619 & 607 & 592 & 608 & 582 & 563 & 608 & 588 & 573 & 612 & 592 & 576 \\
\hline RSS & 15,399 & 8808 & 7817 & 13,305 & 5240 & 4974 & 13,249 & 6097 & 5778 & 13,984 & 6703 & 6190 \\
\hline
\end{tabular}

\subsection{Environmental covariates selection for regression models}

For each training dataset, Pearson correlation analysis was first conducted on all the environmental variables to identify those factors significantly correlated with SOM. MLR using ordinary least squares estimation was computed for those significantly correlated factors in each group, and the variance inflation factor (VIF) were used to remove factors with significant collinearity (Song et al., 2016; Qiu et al., 2012; Wheeler, 2006), here using the rule of thumb that explanatory variables associated with VIF values $<7.5$ indicated no multicollinearity (Qiu et al., 2012). We removed the variable with the highest VIF and then repeated this procedure until all included variables had $\mathrm{VIF}<7.5$. The same environmental covariates were used for GWR and MGWR so that the estimated regression coefficients can be compared. GWR, MGWR and MLR models were then fit and used to predict the A-horizon SOM concentration based on the selected variables for the two study areas using the GWR 4.0 computer program (https://geodacenter.asu.edu/gwr_ software).

\subsection{Evaluations}

Model performance was evaluated by modeling accuracies, mapping results and mapping accuracies. Modeling accuracies was used to examine the reliability of the regression models based on the residual sum of squares (RSS), adjusted R-Squared $\left(\mathrm{R}^{2}\right)$ and AICc. RSS is the sum of the squared residuals in the model. Adjusted R-Squared $\left(R^{2}\right)$ is the measure of goodness of fit for the model accounting for number of predictors and observations. AICc was explained in Section 3.1. AICc is a measure of model performance that mentioned in Section 3.1. AICc is not an absolute measure of goodness of fit but is useful for comparing different models with the same dependent variable. If the AICc values for two models differ by $>3$, the model with the lower AICc is held to be better.

Mapping accuracies were evaluated by applying fitted models to locations not included in model fitting (the independent validation samples) and computing the mean absolute estimation error (MAEE, Eq. (8)) and root mean square error (RMSE, Eq. (9)).

$M A E E=\frac{1}{n} \sum_{i=1}^{n}\left|\hat{y}_{i}-y_{i}\right|$

$R M S E=\sqrt{\frac{1}{n} \sum_{i=1}^{n}\left(\hat{y}-y_{i}\right)^{2}}$

$\hat{y}_{i}$ where $\hat{y}_{i}$ is the estimated SOM concentration at $i$ location, $y_{i}$ is the observed SOM concentration at location $i$, and $n$ is the total number of validation sample.

Because the MGWR is an extension of GWR and MLR, we conducted GWR and MLR to predict the SOM spatial distribution and compared the mapping results, accuracies and regression coefficients of GWR, MLR and MGWR. Besides, there are some other competitive methods in digital soil mapping, such as GWRK (GWR-kriging) (Kumar et al., 2012; Sun et al., 2015), LRK (local regression-kriging) (Sun et al., 2012; Sun et al., 2015), and KED (kriging with an external drift) (Song et al., 2016). We also compared the MGWR method with GWRK (GWRkriging), LRK (local regression-kriging), KED (kriging with an external drift), and $\mathrm{OK}$ (ordinary kriging). The mapping results and mapping accuracy mentioned above were used to evaluate the performances of GWRK, LRK, KED, and OK.

We used R software to conduct the GWRK, KED, and OK method. The LRK method was conducted by using RKGuider software developed by Sun et al. (2012) and set the number of neighborhood points as 80, 90 and 100 (about 40\% of the number of training samples), respectively. We chose the most accurate model validated using validation samples as the final result. For the KED method, a global neighborhood were used (Song et al., 2016).

\section{Results}

\subsection{Environmental covariates selected for regression models}

The Pearson correlation coefficients between SOM concentrate and its environmental covariables for the two study areas are shown in Table 2 and Table 3 . The correlation coefficients using different groups of samples are very similar, indicating that grouping of the samples could represent the distribution of total sample set.

The correlations between SOM and elevation, TWI, height above the nearest drainage (Hand), distance to the nearest drainage (Dand), flow length, valley index, relative position index (RPI), terrain characterization index (TCI) and foot slope were strong in Heshan. This is mainly because of the ability of representing relative slope position and runoff processes of these variables (Gharari et al., 2011; Park and Van De Giesen, 2004). However, correlations between the slope, profile curvature, plan curvature, topographic position index (TPI) and SOM were weak. This indicated that in gentle terrain condition area where the slope length is very long, environmental covariables such as slope and curvature couldn't reflect the spatial distribution of SOM. The likely explanation is that in this low-relief study area those environment variables are nearly homogeneous, for example $90 \%$ of the slope gradients are $<3^{\circ}$.

Different from the Heshan study area, the correlations between SOM and traditional covariates such as elevation, slope, plan curvature, profile curvature were strong, this is mainly because the slope of most of the hilly areas in Xuancheng is relatively steep and short. Height above the nearest drainage, flow length, temperature, precipitation, sandstone and limestone also have strong effect on the distribution of SOM. But the distance to the nearest drainage, relative position index

Table 5

Modeling accuracy of MLR, GWR and MGWR model for Xuancheng.

\begin{tabular}{|c|c|c|c|c|c|c|c|c|c|c|c|c|}
\hline & \multicolumn{3}{|l|}{ Group 1} & \multicolumn{3}{|l|}{ Group 2} & \multicolumn{3}{|l|}{ Group 3} & \multicolumn{3}{|l|}{ Average } \\
\hline & MLR & GWR & MGWR & MLR & GWR & MGWR & MLR & GWR & MGWR & MLR & GWR & MGWR \\
\hline $\mathrm{R}^{2}$ & 0.29 & 0.35 & 0.40 & 0.18 & 0.23 & 0.32 & 0.23 & 0.34 & 0.38 & 0.23 & 0.31 & 0.37 \\
\hline $\mathrm{AICc}$ & 1689 & 1677 & 1671 & 1670 & 1660 & 1651 & 1706 & 1679 & 1662 & 1688 & 1672 & 1661 \\
\hline RSS & 16,383 & 13,329 & 12,616 & 15,116 & 13,489 & 11,625 & 17,500 & 13,383 & 12,682 & 16,333 & 13,400 & 12,308 \\
\hline
\end{tabular}


Table 6

Summary statistics for fixed coefficients and varying variables of MGWR.

\begin{tabular}{|c|c|c|c|c|c|c|c|}
\hline \multicolumn{4}{|c|}{ Heshan farm study area } & \multicolumn{4}{|c|}{ Xuancheng study area } \\
\hline Parameter & Group 1 & Group 2 & Group 3 & Parameter & Group 1 & Group 2 & Group 3 \\
\hline Intercept & 41.7 & 42.04 & 41.49 & Intercept & 28.84 & -3.34 & Varying \\
\hline Flowlen & -0.22 & -0.28 & -0.32 & Slope & 0.280 & 0.145 & Varying \\
\hline RPI & 0.04 & 0.10 & 0.10 & Profic & 0.010 & 0.315 & 0.221 \\
\hline Foot & 0.05 & 0.05 & 0.03 & Precipitation & Varying & Varying & 0.237 \\
\hline Dand & 0.19 & 0.22 & 0.19 & Temperature & Varying & Varying & Varying \\
\hline Elevation & Varying & Varying & Varying & Elevation & Varying & Varying & 0.510 \\
\hline TWI & Varying & Varying & Varying & TWI & 0.092 & 0.083 & 0.099 \\
\hline ValleyI & Varying & Varying & Varying & limestone & Varying & Varying & Varying \\
\hline
\end{tabular}

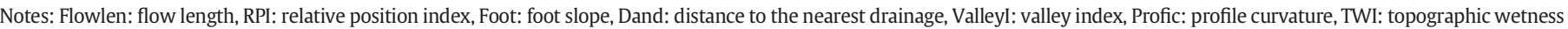
index.

and terrain characterization index show weak correlations with SOM. Results of the two study areas indicated that correlated environmental variables for SOM could be very different due to different pedogenesis based on different environmental conditions.
In this study, the variables correlated with SOM at a significant level higher than 0.05 for each the groups were selected as the start input variables for MLR as mentioned in Section 3.2. After using the VIF indicator to remove variables with collinearity, elevation, valley index,
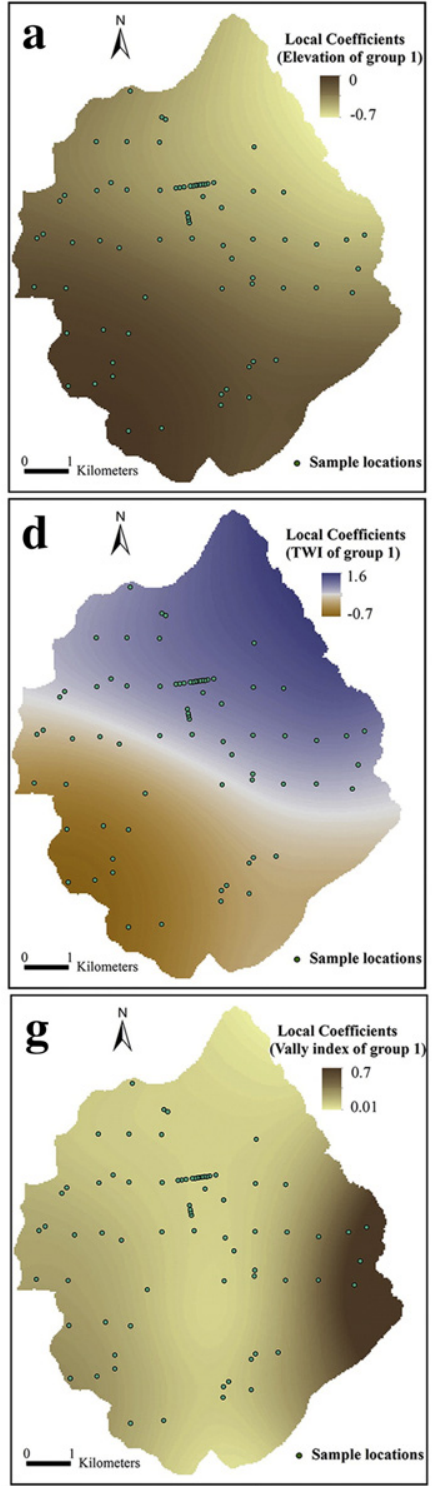

Group 1
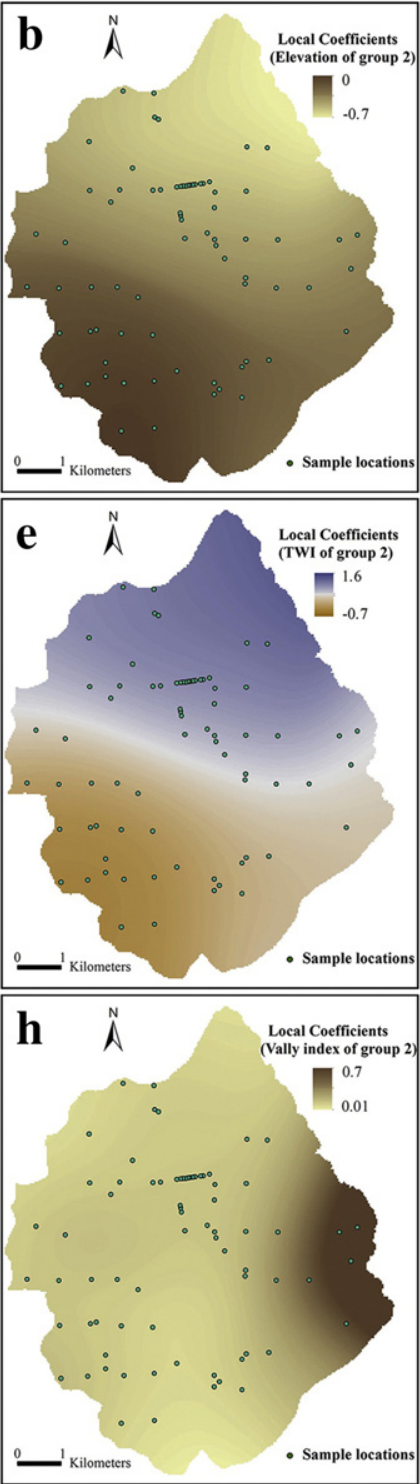

Group 2
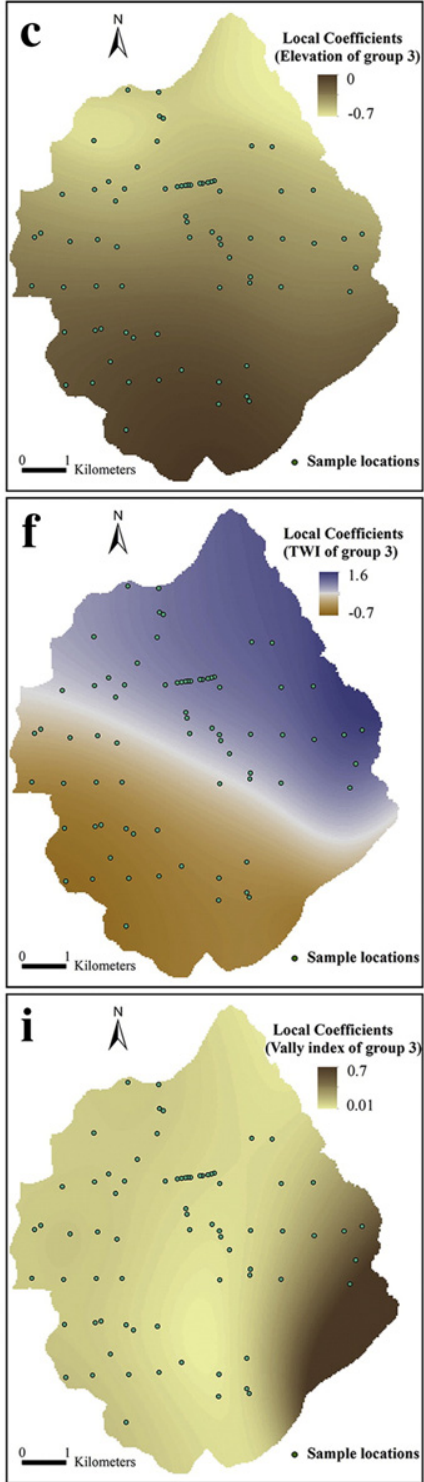

Group 3

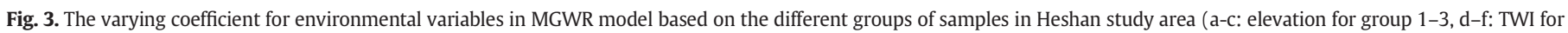
group1-3, g-i: valley index for group 1-3) 
TWI, distance to the nearest drainage, relative position index, foot slope and flow length were selected as predictors for MLR in Heshan farm study area. And elevation, limestone, TWI, profile curvature, slope, precipitation and temperature were selected for Xuancheng study area.

\subsection{Modeling accuracy comparisons between MGWR and GWR, MLR}

The comparison of model fit is shown in Table 4 and Table 5. The MGWR models fit the sample data the best and MLR the worst no matter in which study area, which indicates that the MGWR models explained more SOM variations than MLR or GWR models. The results of the three groups were similar for each study area. The modeling accuracies for Xuancheng study area were generally worse than those for Heshan farm. This is mainly because that the spatial variation of SOM in Xuancheng is more complicated.

\subsection{Regression coefficients of the environmental variables for MGWR}

The varying coefficients of MGWR are shown in Table 6, Fig. 3 and Fig. 4 for the three groups, for each study area.
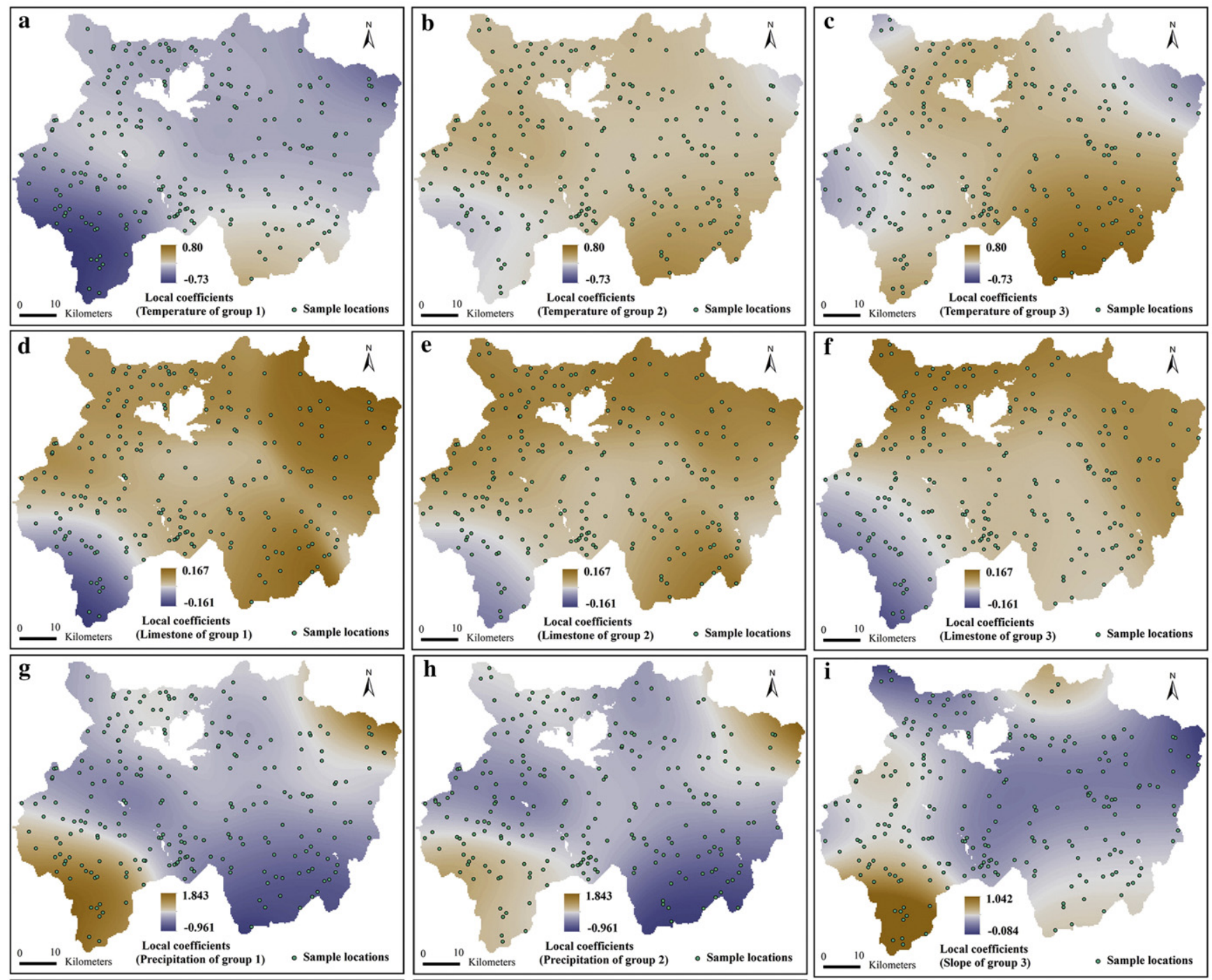

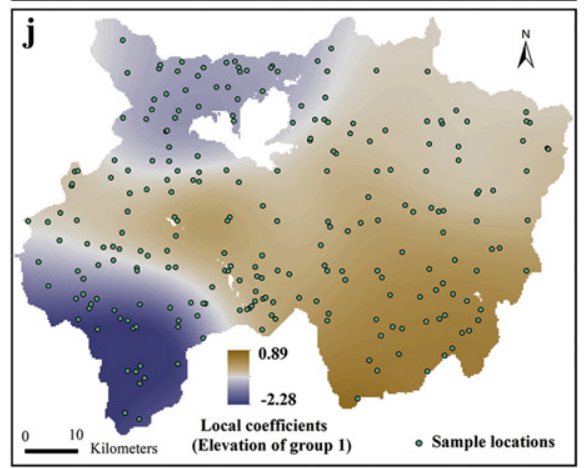

Group 1

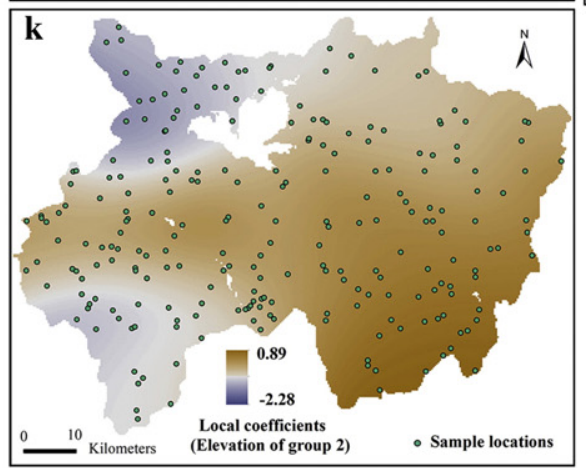

Group 2

\section{Group 3}

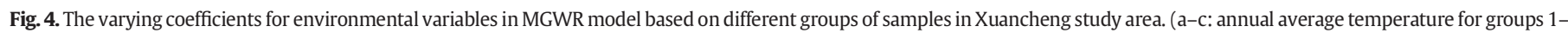
3, d-f: limestone for groups 1-3, g-h: annual average precipitation for groups 1-2, i: slope for group 3, and j-k: elevation for groups 1-2). 
For Heshan study area, the results of variables modeled as fixed or varying based on the three groups were consistent. The coefficients of flow length, relative position index (RPI), foot slope, distance to the nearest drainage were fixed over the space (Table 6). The fixed coefficients of these variables were close to the average values of the local regression coefficients as estimated by GWR The coefficients of both fixed variable or varying variables were similar for each group (Fig. 3 ). The coefficients of elevation, TWI and valley index showed substantial variation across the space (Fig. 3). The effects of elevation indicated a roughly universal negative effect on SOM with a decreasing trend from the northeast to southwest. The effects of TWI varied from negative to strongly positive from southwest to northeast. The local estimated of valley index indicated nearly universal positive effect on SOM concentration and presented significant strong relationships with few localized areas in the east which indicated that valley index play a critical role in the distribution of SOM over this area.

For the Xuancheng study area, the results of variables modeled as fixed or varying in the three groups were different (Table 6). TWI and profile curvature were always fixed over geographic space, average annual temperature and limestone lithology were always varying over geographic space in the three models. However, slope, precipitation and elevation were sometimes varying and sometimes fixed. The main reason could be sample selection that groups may not all represent the full variability. The area of Xuancheng is $5900 \mathrm{~km}^{2}$ but only with 236 training samples (each sample represents $25 \mathrm{~km}^{2}$ ), a lower sampling density than in Heshan which area is $60 \mathrm{~km}$ with 73 training samples (each sample represents $0.8 \mathrm{~km}^{2}$ ). Because of insufficient samples in each GWR window, the local regression coefficients changed with small changes in sample selection. The relationship between environmental covariates and the SOM is not consistent. But this does not hinder MGWR model to find the most accurate training model and achieve good predictive accuracy.

The local estimates of SOM-annual average temperature coefficients showed different patterns for the three sample groups, which relies on the differences of training sample sets. Limestone lithology presented similar trend for each group with negative correlation in the southwest corner and positive correlation in the other regions. The local estimates of annual average precipitation for group 1 and group 2showed similar trends, as well as the local estimates of elevation. The local estimates of elevation-SOM coefficients showed negative relation to SOM only in the low-relief area (north of Xuancheng) or very high elevation area (southwest of Xuancheng) and positive in other hilly region. The maps of local estimates for Xuancheng study area of group 2 were provided in Fig. 4.

\subsection{Semi-variance analysis for GWRK, KED, and OK}

Fig. 5 showed the semi-variance for GWRK, KED, and OK of group 2 as an example for Heshan. Because local regression kriging (LRK) would calculate the semi-variance for every local window, we didn't showed the semi-variance for LRK. It was shown that there were no spatial structures in either original or residual variogram in the Heshan study area for each group. This is mainly because that some samples collected along the transect had quite different SOM concentrations (SOM values ranges from 23.28 to $117.58 \mathrm{~g} / \mathrm{kg}$ with standard deviation of $20.76 \mathrm{~g} /$ $\mathrm{kg}$ ). The variability of SOM in this area is mainly explained by environmental variable in feature space rather than geographic space. It is not suitable to using kriging methods. Under this situation, MGWR can provide an alternative and promising way to predict soil property.

In Xuancheng study area, the experimental variogram for SOM and residuals of regressions showed the spatial dependence (Fig. 6), so besides the GWR and MLR methods, geographic weighted regression kriging (GWRK), local regression-kriging (LRK), kriging with an external drift (KED), and ordinary kriging (OK) were conducted. The exponential models and spherical models were used to fit the variograms for GWRK, KED, and OK respectively to find the most accuracy model (validated using the validation samples) for each method. Take group 2 as an example, for GWRK a spherical models with a 53.72 nugget was fitted, for KED a spherical models with a 57.61 nugget was fitted, and for OK an exponential models with a 36.39 nugget was fitted. In LRK an exponential model was used to fit the variograms. The number of neighborhood points of group 1 was 100 and the number of neighborhood points of groups 2 and 3 were 90 for LRK. The variogram indicated that there was spatial structure in the residuals of the spatial trend, either for KED or for GWRSK, and there was spatial structure in the SOM concentrate for OK for group 2.

\subsection{Mapping results comparisons}

\subsubsection{Heshan study area}

The spatial distribution maps of SOM concentration $(\mathrm{g} / \mathrm{kg})$ predicted by the MGWR, GWR and MLR models showed a similar spatial pattern with good consistency among groups. Fig. 7 showed the distribution of A-horizon soil organic matter maps based on the different models of group 2 as an example for Heshan. High predicted SOM values occurred in the valley, middle SOM values occurred on the middle back slope and low SOM values occurred on the steep slopes and ridges. This matches our understanding of how the terrain factors influence SOM concentration. Erosion is the dominant process that reduces topsoil SOM on steep slopes, while deposition is the dominant process that leads to increase SOM on the lower-to-toe slopes and valley (Zhu et al., 2015). Further, these positions retain more moisture and thus retard SOM mineralization.

The differences between MGWR and GWR, MLR of group 2 were showed in Fig. 8. MLR model predicted a smoother spatial variation than GWR and MGWR. Differences between MGWR and MLR are more widely spread, including valley heads. The range of MLR
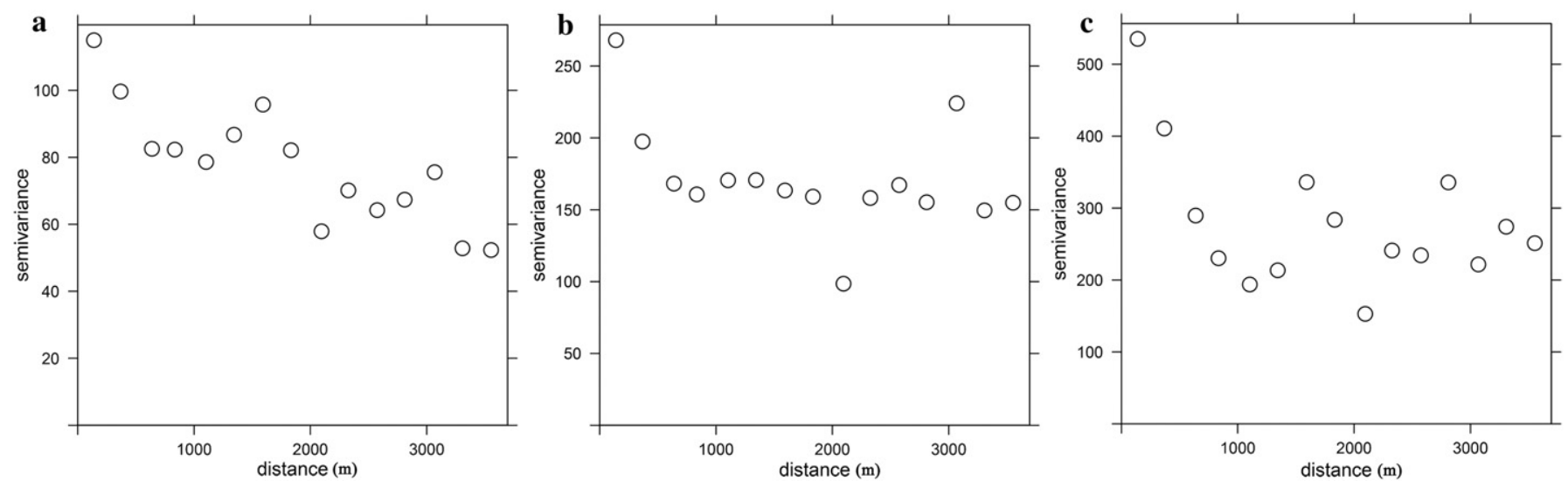

Fig. 5. Experimental residual semi-variance for GWRK (a), semi-variance for KED (b) and semi-variance for OK (c) of Heshan of group 2. 

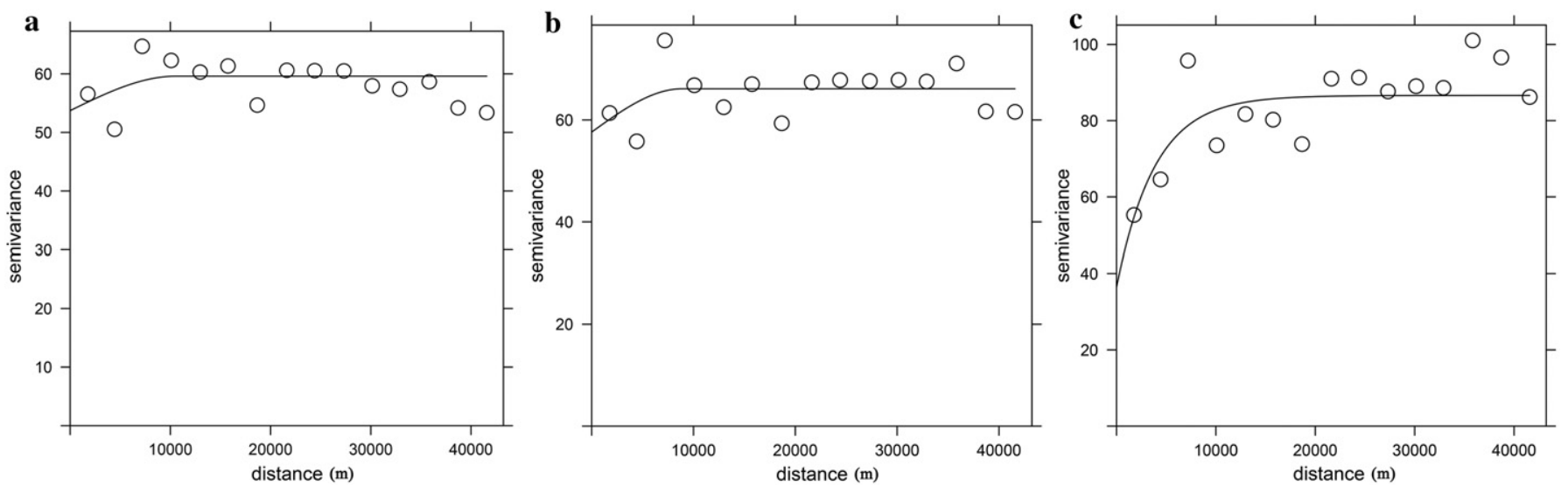

Fig. 6. Experimental residual semi-variance for GWRK (a), semi-variance for KED (b) and semi-variance for OK (c) of Heshan of group 2.

prediction was narrower than for GWR and MGWR and did not match that of the observations. The negative differences between GWR and MGWR mainly located at the foot slope and the slope nearby the valley in the south of study area. The positive differences mainly distributed in the flood plain of the south region and the foot slope of the north region. In the southeast area, the SOM values of nearby observed points are 64.7, 53.5, 52.1, and $139.2(\mathrm{~g} / \mathrm{kg})$ which with large variation. The GWR method focuses more on those local values and enlarged the spatial variations in a small area where the environmental condition actually had gentle variations. Some fixed environmental variables (such as flow length and relative position index) in MGWR would balance the result and make the result a little smoothly. The differences between GWR and MGWR in the south foot slopes and in the north foot slopes were contrary, this is mainly because of the local coefficients generated based on the samples in those areas.

\subsubsection{Xuancheng study area}

The SOM maps with seven mapping approaches (MGWR, GWR, MLR, GWRK, LRK, KED, and OK) in Xuancheng study area were generated. The mapping results of three groups for the same method were similar. All the mapping results for group 2 are displayed as an example in Fig. 9. The OK map (Fig. 9g) shows the most smooth SOM variation, whereas other maps reveal more details and are influenced significantly by the environmental variables (Fig. 9a-f). Besides, MLR and KED with a global neighborhood predicted smoother spatial variations and their ranges of the predicted SOM values are narrower than those methods which fitted the relationships of soil-environmental locally, including MGWR, GWR and LRK.

The differences between MGWR and other methods of group 2 were showed in Fig. 10. The spatial distribution of differences between
MGWR and MLR, GWRK, LRK, OK were more wildly spread than the differences between MGWR and GWR, KED. Large differences between methods for group 2 were observed in the mountainous areas of southwest part, southeast part and north east part (Fig. 10), where the SOM concentration were relatively high. In southwest of Xuancheng, the SOM concentration has a wide range of values $(12-89 \mathrm{~g} / \mathrm{kg}$ ) despite the small sample size $(8,7,10$ samples for groups 1,2 , and 3 respectively). However, its elevation is generally higher than in other areas, and other environmental conditions also show obvious differences. When the selected training samples do not include those samples with smaller SOM concentration, the predicted SOM concentration of other models except for MGWR were high and could not reflect the actual variation of SOM well. Large differences were also found in some other high altitude area, such as southeast part and north east part (Fig. 10). The differences mainly occur in the mountainous areas which exhibit more complicated varying environmental conditions, which may need more training samples.

\subsection{Prediction accuracy comparisons}

The RMSE and MAEE of different methods based on the validation sampling sets are shown in Table 7 for Heshan and Table 8 for Xuancheng. Both RMSEs and MAEEs on average of the MGWR models were the smallest among the different models in the two study areas. The use of MGWR reduced the RMSE of GWR by $10.5 \%$ and $7.6 \%$ on average, reduced the RMSE of MLR by $12.8 \%$ and $9.9 \%$ on average for Heshan and Xuancheng study areas respectively. As for the comparison of GWR and MLR, from the prediction errors on average, GWR performed better than MLR; from the prediction errors of each groups,
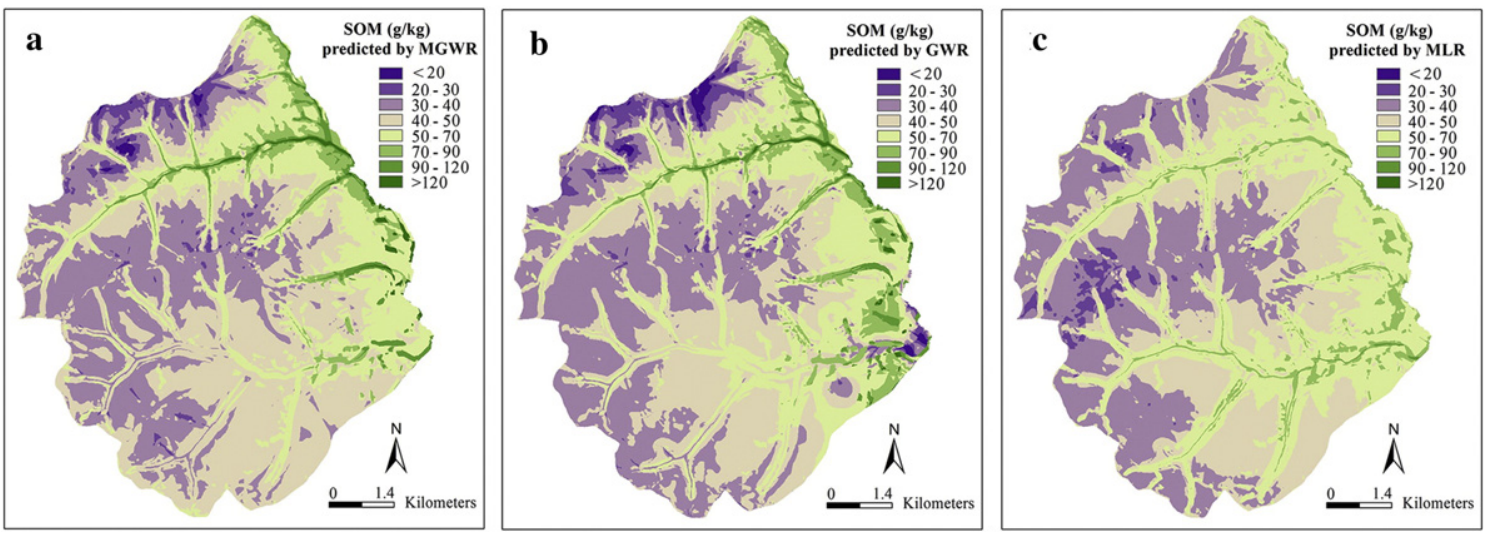

Fig. 7. The distribution of A-horizon soil organic matter maps based on the different model of group 2 for Heshan farm. 

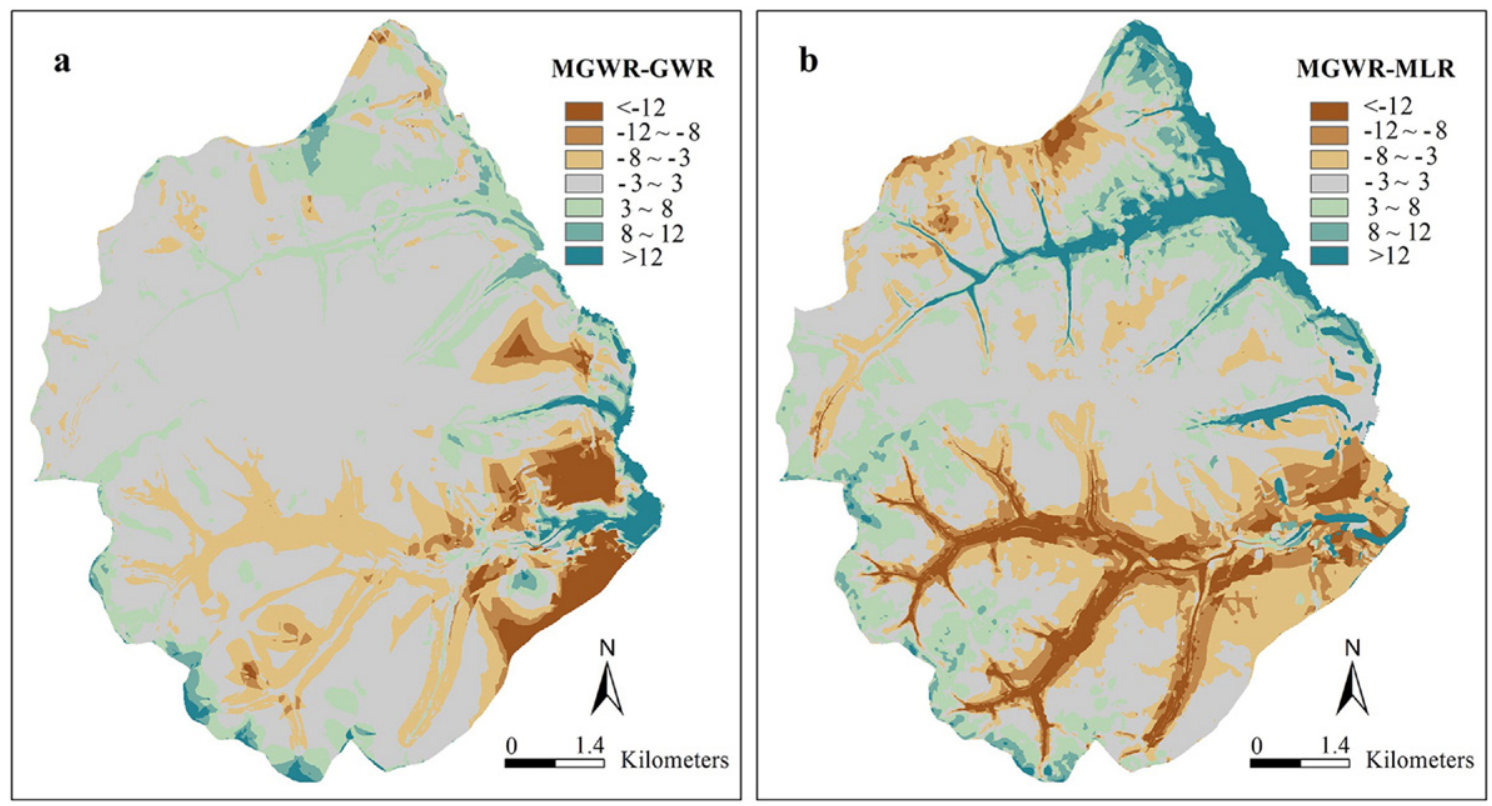

Fig. 8. The difference of A-horizon soil organic matter map based on the different model for group 2 in Heshan farm.
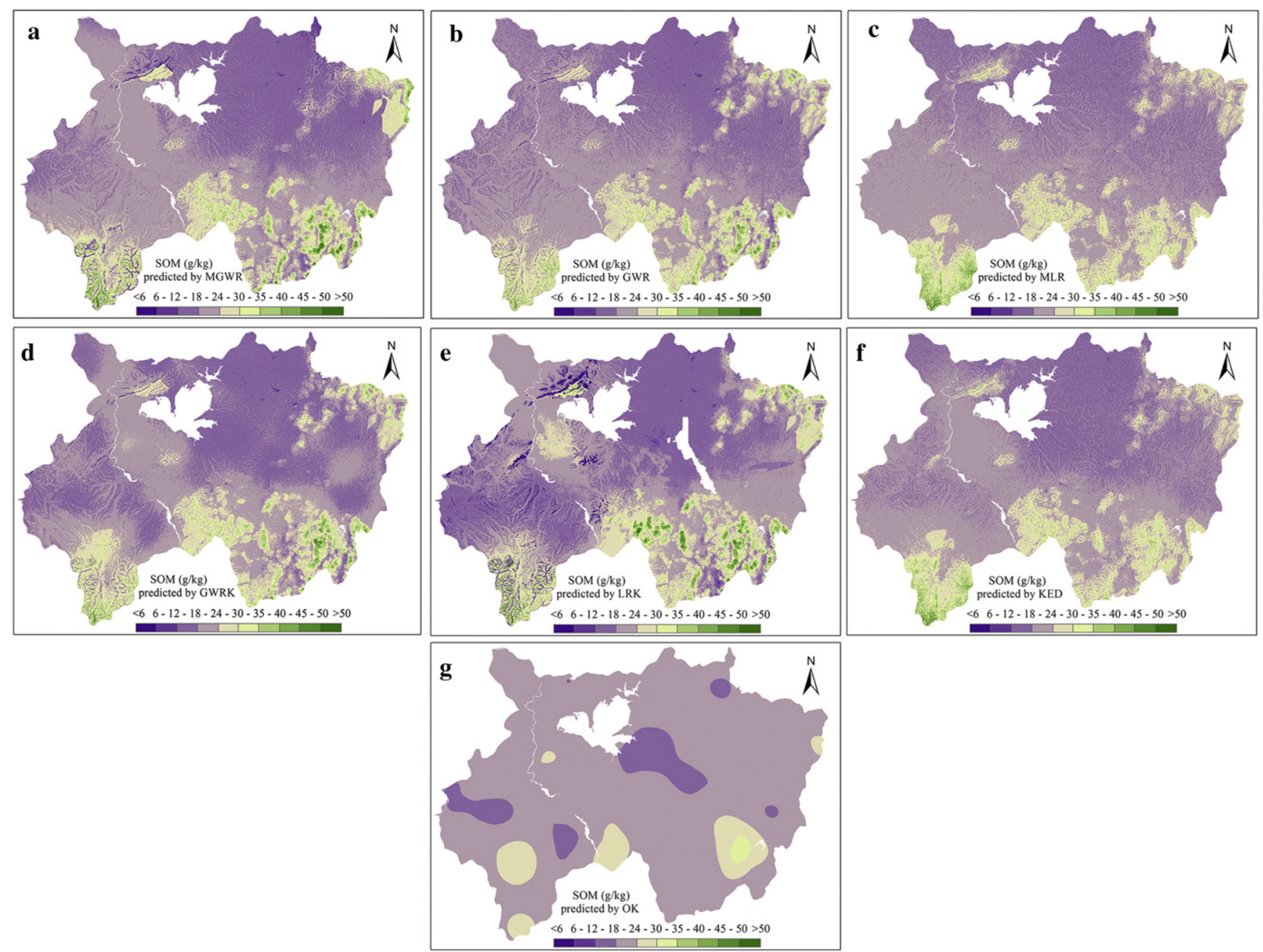

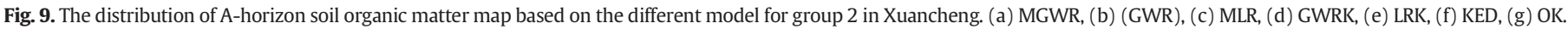




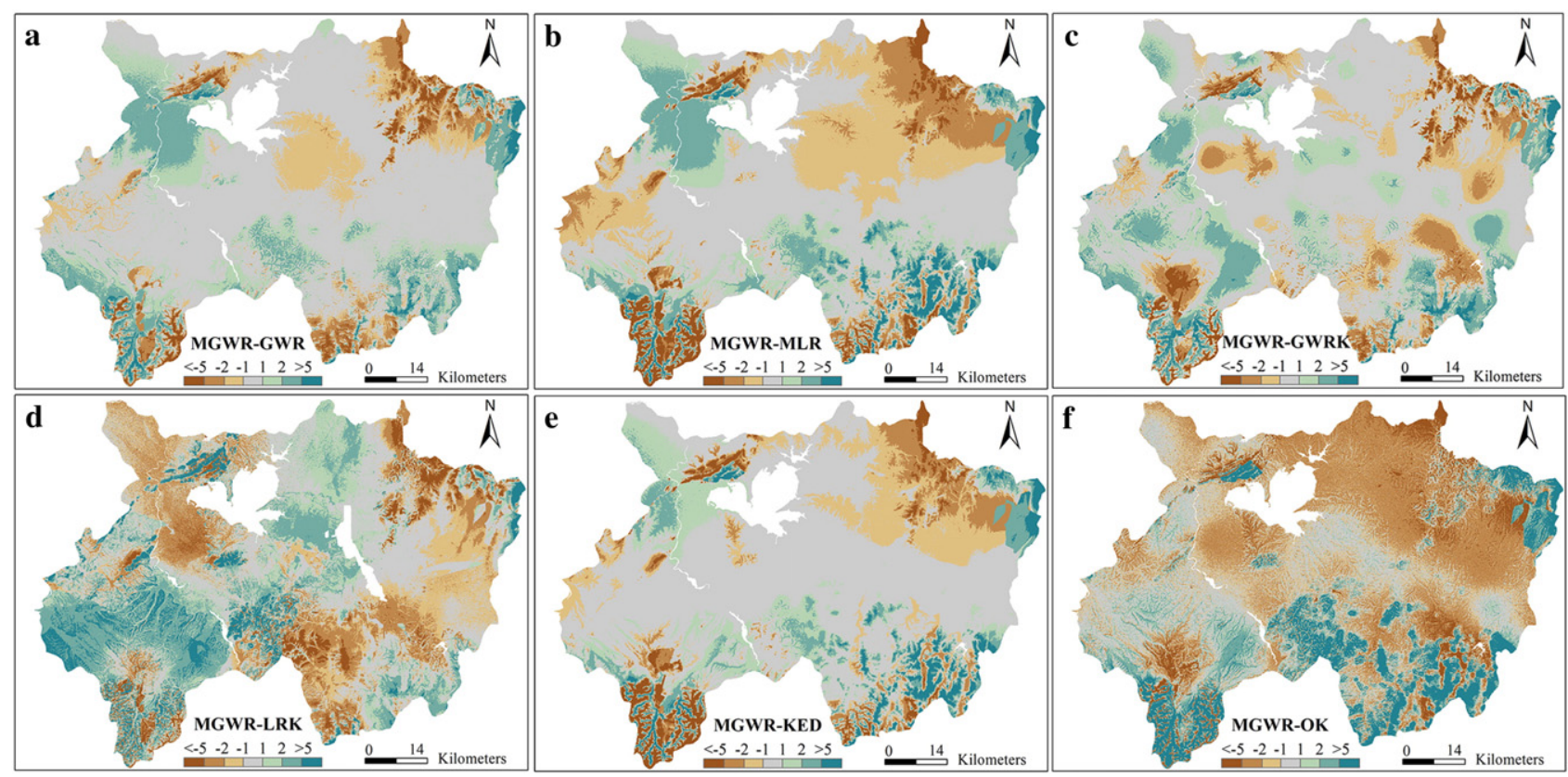

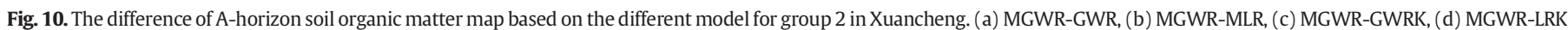
(e) MGWR-KED, (f) MGWR-OK.

GWR didn't always performed better than MLR in either of the two study areas.

As for the comparison of the seven models in Xuancheng study area (Table 8), it was shown that the predicted accuracy of MGWR were highest among those methods for group 1 and 2 . In group 3, the MGWR have higher prediction accuracy than GWR, MLR, KED, and OK, but lower than LRK and GWRK. In this group, the prediction accuracies of regression methods (MGWR, GWR, and MLR) had no significant difference, the results of regression kriging (GWRK, LRK) showed better prediction accuracies except KED, which had slightly lower compared with MGWR.

\section{Discussion}

Our key research question in this study is whether the prediction result can be improved by adaptive coefficient (varying and fixed) according to the variation of environmental variables as implemented in the MGWR method. The results of the two case studies of comparisons between MGWR and other methods showed the potential of MGWR. However, there are some issues that need attention. In Heshan the varying and fixed variables in different groups were consistent, but in Xuancheng study they were not. Except for the difference of complexity and variability of the landscapes in the two study areas, a reason is difference of sampling densities $\left(25 \mathrm{~km}^{2}\right.$ in Xuancheng vs. $0.8 \mathrm{~km}^{2}$ per observation in Heshan). This indicates that the sampling density in Xuancheng was not adequate to capture the relationships between SOM and its environmental co-variables. The required density depends on the complexity of the soil-landscape relations. We do not propose any method to determine an adequate density, as it seems this can only be determined post hoc by our method of checking the consistency of MGWR over subsets of observations. The relationships between environmental covariates and SOM are also different in both MLR and GWR among the different groups. Calibration of all models including MGWR, GWR and MLR are data-driven and thus sensitive to the data density: higher density should lead to more reliable models, especially those with local adaptations such as GWR and MGWR.
When the sample is sparse for a study area, such as Xuancheng, the ordinary kriging is usually worse than regression models or regression kriging methods. In total, from the RMSE on average we found that for the Xuancheng study area with complex environmental conditions at a regional scale, the accuracy of predictions can be improved by local regression coefficients as implemented in MGWR (with an average RMSE of $8.05 \mathrm{~g} / \mathrm{kg}$ ), GWR (with an average RMSE of $8.71 \mathrm{~g} / \mathrm{kg}$ ), GWRK (with an average RMSE of $8.44 \mathrm{~g} / \mathrm{kg}$ ) and LRK (with an average RMSE of $8.65 \mathrm{~g} / \mathrm{kg}$ ) instead of global regression coefficients as in MLR (with an average RMSE of $8.93 \mathrm{~g} / \mathrm{kg}$ ) and KED with a global search neighborhood ( with an average RMSE of $8.96 \mathrm{~g} / \mathrm{kg}$ ). The accuracy of predictions can be improved by adaptive coefficient (varying and fixed) according to the variation of environmental variables as implemented in the MGWR method compared with the methods that only considering the local relationships.

When comparing MGWR with GWR or MLR, the improvement of MGWR in the Xuancheng study area (decrease of RMSE by $7.6 \%$ and 9.9\%) was less than that in the Heshan study area (decrease of RMSE by $10.5 \%$ and $12.8 \%$ ). In Heshan study area, the mean absolute difference between MGWR and GWR for three groups on average is $3.28 \mathrm{~g} / \mathrm{kg}$, and the range of SOM values of the samples is 22.45 to $139.2 \mathrm{~g} / \mathrm{kg}$ with a mean of $45 \mathrm{~g} / \mathrm{kg}$. In Xuancheng study area, the mean absolute difference between MGWR and GWR for three groups on average is $1.40 \mathrm{~g} / \mathrm{kg}$, and the range of SOM values of the samples is 4.37 to $89.12 \mathrm{~g} / \mathrm{kg}$ with a mean of $21.44 \mathrm{~g} / \mathrm{kg}$. From our result, the results from MGWR and GWR were relatively similar for the larger study area. MGWR will probably provide better results in comparatively smaller study areas, and probably the

Table 7

The comparison of prediction accuracy between MGWR and GWR, MLR in Heshan study area.

\begin{tabular}{|c|c|c|c|c|c|c|c|c|}
\hline & \multicolumn{2}{|c|}{ Group 1} & \multicolumn{2}{|c|}{ Group 2} & \multicolumn{2}{|c|}{ Group 3} & \multicolumn{2}{|c|}{ Average } \\
\hline & RMSE & MAEE & RMSE & MAEE & RMSE & MAEE & RMSE & MAEE \\
\hline MGWR & 8.79 & 6.56 & 12.45 & 8.88 & 12.07 & 8.19 & 11.10 & 7.88 \\
\hline GWR & 9.49 & 7.22 & 15.25 & 10.36 & 12.45 & 8.88 & 12.40 & 8.70 \\
\hline MLR & 9.57 & 7.40 & 15 & 9.00 & 13.62 & 8.69 & 12.73 & 8.36 \\
\hline
\end{tabular}


Table 8

The comparison of prediction accuracy between MGWR and GWR, MLR, GWRK, LRK, KED, OK in Xuancheng study area.

\begin{tabular}{|c|c|c|c|c|c|c|c|c|}
\hline & \multicolumn{2}{|c|}{ Group 1} & \multicolumn{2}{|c|}{ Group 2} & \multicolumn{2}{|c|}{ Group 3} & \multicolumn{2}{|c|}{ Average } \\
\hline & RMSE & MAEE & RMSE & MAEE & RMSE & MAEE & RMSE & MAEE \\
\hline MGWR & 7.60 & 5.59 & 9.31 & 6.35 & 7.23 & 5.83 & 8.05 & 5.92 \\
\hline GWR & 8.45 & 6.49 & 10.19 & 6.82 & 7.5 & 5.88 & 8.71 & 6.40 \\
\hline MLR & 9.23 & 6.76 & 10.12 & 6.73 & 7.44 & 5.87 & 8.93 & 6.45 \\
\hline GWRK & 8.53 & 6.33 & 10.07 & 6.67 & 6.72 & 5.36 & 8.44 & 6.12 \\
\hline LRK & 8.61 & 6.45 & 10.70 & 7.13 & 6.65 & 5.30 & 8.65 & 6.29 \\
\hline KED & 9.33 & 6.83 & 10.17 & 6.62 & 7.39 & 5.85 & 8.96 & 6.43 \\
\hline $\mathrm{OK}$ & 7.68 & 5.85 & 11.49 & 6.96 & 8.08 & 6.37 & 9.08 & 6.39 \\
\hline
\end{tabular}

results from both MGWR and GWR techniques will be similar for larger study areas.

\section{Conclusions}

In this study, the limitation of present regression models assumed the relationships between soil and environmental variables to be fixed throughout a given region (for MLR) or to be varying for every variables (for GWR), were addressed. A mixed geographically weighted regression method (MGWR) was tested in two study areas at different scales and compared with GWR, MLR, GWRK, LRK, KED, and OK. The results of the two case studies showed that the models built using MGWR fitted all the three training datasets the best and prediction errors of the predicted SOM using MGWR based on the validation datasets were lowest when compared with GWR and MLR. MGWR will possibly provide better results in comparatively smaller study areas, and the results from both MGWR and GWR will probably be similar for larger study areas. As for the comparison with GWRK, LRK, KED, and OK, MGWR also showed a good competitiveness. The results indicate that the accuracy of predictions can be improved by adaptive coefficient (varying and fixed) according to the variation of environmental variables as implemented in MGWR compared with the methods considering only the local or global relationships. Besides, MGWR could give a good explanation of the relationships between soil and its environmental covariates and support applications such as land resource management, etc. Thus, MGWR can provide an alternative and promising way to predict soil property, especially when the experimental variogram for soil property or the residuals of regression show no spatial dependence so that kriging and regression-kriging methods were not appropriate.

\section{Acknowledgments}

The study was supported by National Natural Science Foundation of China (Project No.: 41431177, 41471178, 41530749), Natural Science Research Program of Jiangsu (Project No.: 14KJA170001), National Basic Research Program of China (Project No.: 2015CB954102), National Key Technology Innovation Project for Water Pollution Control and Remediation (Project No.: 2013ZX07103006). Supports to A-Xing Zhu through the Vilas Associate Award, the Hammel Faculty Fellow Award, the Manasse Chair Professorship from the University of WisconsinMadison, and the "One-Thousand Talents" Program of China are greatly appreciated. The authors thank the three reviewers and Alex. McBratney (University of Sydney) for their valuable suggestions. The authors also thank the Dr. Wei Sun (Chinese Academy of Agriculture Sciences) to provide the RKGuider software.

\section{References}

Bishop, T.F.A., Mcbratney, A.B., 2001. A comparison of prediction methods for the creation of field-extent soil property maps. Geoderma 103 (1), 149-160.

Brunsdon, C., Fotheringham, A.S., 1999. Some notes on parametric significance tests for geographically weighted regression. J. Reg. Sci. 39, 497-524.
Brunsdon, C., Fotheringham, A.S., Charlton, M., 1996. Geographically weighted regression: a method for exploring spatial nonstationarity. Geogr. Anal. 28, 281-289.

Brus, D.J., Heuvelink, G.B., 2007. Optimization of sample patterns for universal kriging of environmental variables. Geoderma 138 (1), 86-95.

Chung, N., Alexander, M., 2002. Effect of soil properties on bioavailability and extractability of phenanthrene and atrazine sequestered in soil. Chemosphere 48, 109-115.

Du, F., Zhu, A.X., Liu, J., Band, L., 2015. Soil property variation mapping through data mining of soil category maps for hydrological modelling. Hydrol. Process. 29, 2491-2503.

Fotheringham, A.S., Brunsdon, C., Charlton, M., 2002. Geographically Weighted Regression: the Analysis of Spatially Varying Relationships. Wiley, West Sussex.

Gharari, S., Hrachowitz, M., Fenicia, F., Savenije, H.H.G., 2011. Hydrological landscape classification: investigating the performance of HAND based landscape classifications in a central European meso-scale catchment. Hydrol. Earth Syst. Sci. 15 (11), 3275-3291.

Helbich, M., Brunauer, W., 2016. Mixed Geographically Weighted Regression for Hedonic House Price Modelling in Austria (na).

Henderson, B.L., Bui, E.N., Moran, C.J., Simon, D.a.P., 2005. Australia-wide predictions of soil properties using decision trees. Geoderma 124 (3), 383-398.

Hengl, T., Heuvelink, G.B.M., Stein, A., 2004. A generic framework for spatial prediction of soil variables based on regression-kriging. Geoderma 120 (1), 75-93.

Hengl, T., Heuvelink, G.B.M., Rossiter, D.G., 2007. About regression-kriging: from equations to case studies. Comput. Geosci. 33, 1301-1315.

Jenness, J., 2005. Topographic Position Index. ((tpi jen.avx) extension for ArcView 3.x, v. 1.2. Jenness Enterprises. Available at:) http://www.jennessent.com/arcview/tpi.htm.

Kumar, S., Lal, R., Liu, D.S., 2012. A geographically weighted regression kriging approach for mapping soil organic carbon stock. Geoderma 189-190, 627-634.

Lesch, S.M., Strauss, D.J., Rhoades, J.D., 1995. Spatial prediction of soil salinity using electromagnetic induction techniques 1 . Statistical prediction models: a comparison of multiple linear regression and cokriging. Water Resour. Res. 31, 373-386.

Li, Y., 2010. Can the spatial prediction of soil organic matter contents at various sampling scales be improved by using regression kriging with auxiliary information? Geoderma 159, 63-75

Liu, G.S., Jiang, N.H., Zhang, L.D., Liu, Z.L., 1996. Soil Physical and chemical analysis and description of soil profile. China Standardization Publishing House, Beijing, pp. 131-134 (In Chinese)

Mcbratney, A.B., Mendonca, S.M.L., Minasny, B., 2003. On digital soil mapping. Geoderma $117,3-52$.

Mei, C.L., He, S.Y., Fang, K.T., 2004. A note on the mixed geographically weighted regression model. J. Reg. Sci. 44 (1), 143-157.

Mei, C.L., Wang, N., Zhang, W.X., 2006. Testing the importance of the explanatory variables in a mixed geographically weighted regression model. Environ. Plan. A 38, 587-598.

Mishra, U., Riley, W.J., 2012. Alaskan soil carbon stocks: spatial variability and dependence on environmental factors. Biogeosciences 9 (9), 3637-3645.

Mishra, U., Torn, M.S., Masanet, E., Ogle, S.M., 2012. Improving regional soil carbon inventories: combining the IPCC carbon inventory method with regression kriging. Geoderma 189, 288-295.

Moore, I.D., Gessler, P.E., Nielsen, G.A., Peterson, G.A., 1993. Soil attribute prediction using terrain analysis. Soil Sci. Soc. Am. J. 57, 443-452.

Nakaya, T., 2012. GWR4 User Manual. (WWW document) http://www.st-andrews.ac.uk/ geoinformatics/wp-content/uploads/GWR4manual_201311.pdf.

Nakaya, T., Fotheringham, A.S., Charlton, M., Brunsdon, C., 2005. Geographically weighted Poisson regression for disease associative mapping. Stat. Med. 24.

Nakaya, T., Fotheringham, A.S., Charlton, M., Brunsdon, C., 2009. Semiparametric Geographically Weighted Generalised Linear Modelling in GWR 4.0.

Nelson, D.W., Sommers, L.E., 1982. Total carbon, organic carbon, and organic mat-ter. In: Page, A.L., Miller, R.H., Keeney, D.R. (Eds.), Methods of Soil AnalysisPart2 - Chemical and Microbiological Properties. ASA-SSSA, Madison, Wisconsin, pp. USA539-USA594.

Odeh, I.O., Mcbratney, A.B., 2000. Using AVHRR images for spatial prediction of clay content in the lower Namoi Valley of eastern Australia. Geoderma 97 (3), 237-254.

Park, S.J., Van De Giesen, N., 2004. Soil-landscape delineation to define spatial sampling domains for hillslope hydrology. J. Hydrol. 295, 28-46.

Pecci, F., Sassi, M., 2008. A Mixed geographically Weighted Approach to Decoupling and Rural Development in the EU-15 (L. Bartova).

Qin, C.Z., Zhu, A.X., Pei, T., Li, B.L., Zhou, C.H., Yang, L., 2007. An adaptive approach to selecting a flow-partition exponent for a multiple-flow-direction algorithm. Int. J. Geogr. Inf. Sci. 21 (4), 443-458.

Qin, C.Z., Lu, Y.J., Bao, L.L., Zhu, A.X., Qiu, W.L., Cheng, W.M., 2009a. Simple digital terrain analysis software (SimDTA 1.0) and its application in fuzzy classification of slope positions. Glob. J. Geol. Sci. 11 (6), 737-743.

Qin, C.Z., Zhu, A.X., Shi, X., Li, B.L., Pei, T., Zhou, C.H., 2009b. Quantification of spatial gradation of slope positions. Geomorphology 110 (3), 152-161.

Qin, C.Z., Zhu, A.X., Qiu, W.L., Lu, Y.J., Li, B.L., Pei, T., 2012. Mapping soil organic matter in small low-relief catchments using fuzzy slope position information. Geoderma 171, 64-74.

Qiu, Y., Fu, B., Wang, J., Chen, L., 2003. Spatiotemporal prediction of soil moisture content using multiple-linear regression in a small catchment of the Loess Plateau, China. Catena 54, 173-195.

Qiu, B.W., Zhong, M., Zeng, C.Y., Tang, Z.H., Chen, C.C., 2012. Effect of topography and accessibility on vegetation dynamic pattern in Mountain-hill region. J. Mt. Sci. 9, 879-890.

Reza Pahlavan Rad, M., Toomanian, N., Khormali, F., Brungard, C.W., Bayram Komaki, C., Bogaert, P., 2014. Updating soil survey maps using random forest and conditioned Latin hypercube sampling in the loess derived soils of northern Iran. Geoderma 232, 97-106.

Shary, P.A., Sharaya, L.S., Mitusov, A.V., 2002. Fundamental quantitative methods of land surface analysis. Geoderma 107, 1-32. 
Skidmore, A.K., 1990. Terrain positions mapped from a gridded digital elevation model. Int. J. Geogr. Inf. Syst. 4 (1), 33-49.

Song, X.D., Brus, D.J., F. L., D.C.,.L., Zhao, Y.G., Yang, J.L., G.L., Z., 2016. Mapping soil organic carbon content by geographically weighted regression: a case study in the Heihe River basin, China. Geoderma 261, 11-22.

Stoorvogel, J.J., Kempen, B., Heuvelink, G.B.M., De Bruin, S., 2009. Implementation and evaluation of existing knowledge for digital soil mapping in Senegal. Geoderma 149 (1), 161-170.

Sugiura, N., 1978. Further analysts of the data by akaike's information criterion and the finite corrections: further analysts of the data by akaike's. Communications in Statistics-Theory and Methods 7 (1), 13-26.

Sumfleth, K., Duttmann, R., 2008. Prediction of soil property distribution in paddy soil landscapes using terrain data and satellite information as indicators. Ecol. Indic. 8 (5), 485-501.

Sun, W., Minasny, B., Mcbratney, A., 2012. Analysis and prediction of soil properties using local regression-kriging. Geoderma 171, 16-23.

Sun, W., Zhu, Y.Q., Huang, S.L., Guo, C.X., 2015. Mapping the Mean Annual Precipitation of China Using Local Interpolation Techniques.

Taghizadeh-Mehrjardi, R., Sarmadian, F., Minasny, B., Triantafilis, J., Omid, M., 2014. Digital mapping of soil classes using decision tree and auxiliary data in the Ardakan region, Iran. Arid Land Research and Management 28 (2), 147-168.

Thompson, J.A., Pena-Yewtukhiw, E.M., Grove, J.H., 2006. Soil-landscape modeling across a physiographic region: topographic patterns and model transportability. Geoderma 133, 57-70.

Walter, C., Mcbratney, A.B., Donuaoui, A., Minasny, B., 2001. Spatial prediction of topsoil salinity in the Chelif valley, Algeria, using local ordinary kriging with local variograms versus whole-area variogram. Aust. J. Soil Res. 39, 259-272.

Wang, K., Zhang, C., Li, W., 2013. Predictive mapping of soil total nitrogen at a regional scale: a comparison between geographically weighted regression and cokriging. Appl. Geogr. 42, 73-85.

Wei, C.H., Qi, F., 2012. On the estimation and testing of mixed geographically weighted regression models. Econ. Model. 29, 2615-2620.
Wheeler, D.C., 2006. Diagnostic Tools and Remedial Methods for Collinearity in Linear Regression Models with Spatially Varying Coefficients. The Ohio State University pp. 65-97.

Winklerprins, A.M., 1999. Insights and applications varying soil knowledge: a tool for sustainable land management. Soc. Nat. Resour. 12 (2), 151-161.

Yang, Y., Fang, J., Tang, Y., Ji, C., Zheng, C., He, J., Zhu, B., 2008. Storage, patterns and controls of soil organic carbon in the Tibetan grasslands. Glob. Chang. Biol. 14 (7), 1592-1599.

Yang, L., Zhu, A.X., Oi, F. Qin, CZ Li, B., Pei, T., 2013. An integrative hierarchical stepwise sampling strategy for spatial sampling and its application in digital soil mapping. Int. J. Geogr. Inf. Sci. 27 (1), 1-23.

Yang, L., Zhu, A.X., Zhao, Y.G., D.C., L., G.L., Z., S.J., Z., Band, L.E., 2016. Regional Soil Mapping Using Multi-Grade Representative Sampling and a Fuzzy Membership Based Mapping Approach, Pedosphere. Accept (in press).

Zhang, C., Tang, Y., Xu, X., Kiely, G., 2011. Towards spatial geochemical modelling: use of geographically weighted regression for mapping soil organic carbon contents in Ireland. Appl. Geochem. 26 (7), 1239-1248.

Zhang, S.W., Huang, Y.F., Shen, C.Y., Ye, H.C., Du, Y.C., 2012. Spatial prediction of soil organic matter using terrain indices and categorical variables as auxiliary information. Geoderma 171-172, 35-43.

Zhang, S.J., Zhu, A.X., Liu, J., Yang, L., Qin, C.Z., An, Y.M., 2016. An heuristic uncertainty directed field sampling design for digital soil mapping. Geoderma 267, 123-136.

Zhao, M.S., Rossiter, D.G., Li, D.C., Zhao, Y.G., Liu, F., Zhang, G.L., 2014. Mapping soil organic matter in low-relief areas based on land surface diurnal temperature difference and a vegetation index. Ecol. Indic. 39, 120-133.

Zhu, A.X., Yang, L., Bao, L.L., Qin, C.Z., Pei, T., Liu, B.Y., 2010. Construction of membership functions for predictive soil mapping under fuzzy logic. Geoderma 155, 164-174

Zhu, A.X., Liu, J., Du, F., Zhang, S.J., Qin, C.Z., Burt, J., Scholten, T., 2015. Predictive soil mapping with limited sample data. Eur. J. Soil Sci. 66, 535-547.

Zornoza, R., Mataix-Solera, J., Guerrero, C., Arcenegui, V., García-Orenes, F., MataixBeneyto, J., Morugán, A., 2007. Evaluation of soil quality using multiple lineal regression based on physical, chemical and biochemical properties. Sci. Total Environ. 378 (1), 233-237. 